\title{
Structurally Engineered Hollow Graphitized Carbon Nanocages as High-Performance Anodes for Potassium Ion Batteries
}

Zhanpeng Li, ${ }^{\S}$ Ning Sun, ${ }^{\S}$ Razium Ali Soomro, Zhaoruxin Guan, Li Ma, Mingchi Jiang, Qizhen Zhu, and $\mathrm{Bin} \mathrm{Xu}^{*}$

Cite This: https://dx.doi.org/10.1021/acsnano.0c01150

Read Online

ABSTRACT: Graphite is an attractive anode with high capacity and low cost for potassium ion batteries (PIBs) but suffers from poor cycle performance due to the large interlayer expansion during the potassiation/depotassiation process. Here, we propose structurally engineered hollow graphitized carbon nanocages (HGCNs) as efficient anode materials for PIBs. The HGCNs were synthesized using a one-pot, self-template and self-graphitization approach where direct pyrolysis of nickel citrate converts citrate chains into carbon-shell and simultaneously reduces $\mathrm{Ni}^{2+}$ to form a $\mathrm{Ni}$ metal core. This nickel core serves as not only a hard-template to create hollow-cage structure but also a catalyst to facilitate the graphitization of the

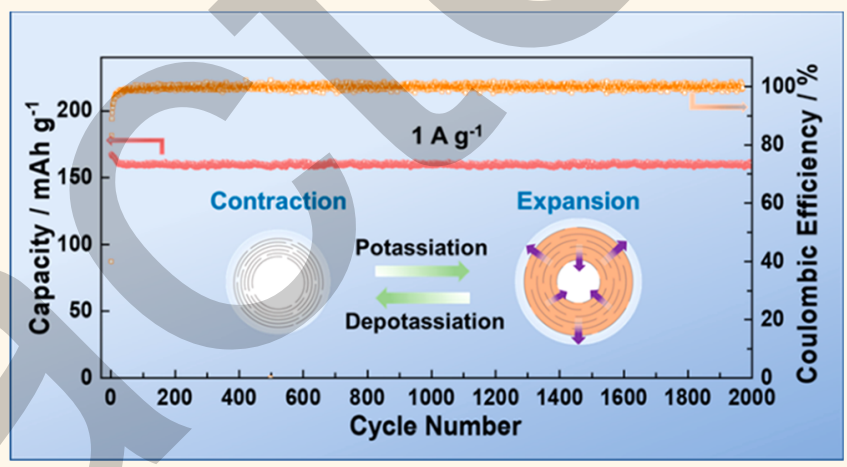
carbon-shell. The HGCNs synthesized at $1000{ }^{\circ} \mathrm{C}$ (HGCN1000), with its highly graphitized carbon-cage and developed porosity, exhibited an impressive K-storage capacity of 402.2 $\mathrm{mAh} \mathrm{g}^{-1}$ at a current density of $30 \mathrm{~mA} \mathrm{~g}^{-1}$. The synergic combination of hollow morphology with graphitized carbon layers configured a stable structure capable of enduring extreme deformation, endowing HGCN-1000 a robust cyclic stability with a capacity retention of $95.9 \%$ over 2000 cycles at $1 \mathrm{~A} \mathrm{~g}^{-1}$. The proposed strategy provides an efficient route to combat the bottleneck cycling instability issue of graphitic carbon with hollow-graphitized carbon nanocages as promising anode materials for PIBs.

KEYWORDS: potassium-ion batteries, anode, hollow nanocages, graphitized carbon, structural engineering

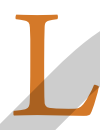
ithium-ion batteries (LIBs) are among the most efficient energy storage systems based on their high energy density and long cycle life. However, the growing-scarcity and production cost of lithium sources have become an increasing concern of the energy community, considering the explosive growth of large-scale energy storage system for renewable energy utilization in the near future. Thus, low-cost materials that are abundant in resources are highly desirable for future mass-production of rechargeable energy devices. In this context, sodium-ion batteries (SIBs) and potassium-ion batteries (PIBs) have gathered significant attention from the energy-storage community. ${ }^{1,2}$ In particular, PIBs, where $\mathrm{K}$ ion shares the same operational mechanism and close redox potential $\left(\mathrm{K} / \mathrm{K}^{+}(-2.93 \mathrm{~V})\right)$ to $\mathrm{Li}$ ion $\left(\mathrm{Li} / \mathrm{Li}^{+}\right.$ $(-3.04 \mathrm{~V}))$, reveals its promising perspective in the future energy applications. ${ }^{3}$

In terms of PIBs, a variety of different materials such as carbon, ${ }^{4-6}$ alloys, $^{7-9}$ transition-metal oxides/sulfides, ${ }^{10,11}$ and red phosphorus ${ }^{12,13}$ have been explored as potential anode materials. Among them, carbon-based materials are regarded as the most promising anodes for practical application. Especially, graphite anode has proven to be a superior candidate, as its layered structure is available for $\mathrm{K}^{+}$intercalation to form the stage-one $\mathrm{K}$-graphite intercalation compounds $\left(\mathrm{KC}_{8}\right)$ with a high reversible capacity of $279 \mathrm{mAh} \mathrm{g}^{-1}$. However, the intercalation of bigger $\mathrm{K}^{+}\left(1.38 \AA\right.$ of $\mathrm{K}^{+}$vs $0.76 \AA$ of $\left.\mathrm{Li}^{+}\right)$ usually results in $60 \%$ overexpansion of graphite's interlayer distance, $^{14,15}$ leading to severe structural fractures, which compromises the cyclic stability and rate capability of the designed anode. This structural instability is a serious concern

Received: February 10, 2020

Accepted: April 14, 2020

Published: April 14, 2020 
before graphite-anodes could be advised for practical applications. To circumvent this issue, the use of selected electrolytes and binders has been proposed. For example, the use of ethylene carbonate:propylene carbonate (EC:PC) based electrolyte for PIBs is reported to exhibit a higher initial columbic efficiency (ICE) and better cyclability than EC:diethyl carbonate (DEC) or EC:dimethyl carbonate (DMC). ${ }^{16}$ Similarly, improved cycle performance was achieved when carboxymethylcellulose (CMC) was used in place of conventional polyvinylidene fluoride (PVDF) binder. $^{17}$ Though the rational choice of electrolyte and binder could improve the performance of graphitic materials in PIBs, the structural engineering of graphitic material into a configuration that could endure large volume expansion is a more fundamental approach to obtain prominent and enhanced improvement in the electrochemical K-storage performance of graphitic materials. In this context, $\mathrm{Ji}$ et al. reported the synthesis of polynanocrystalline graphite using chemical vapor deposition (CVD) technique. ${ }^{18}$ The strategy resulted in polynanocrystalline graphite composed of randomly oriented graphitic nanodomains, with short-range ordered and longrange disordered structures, which exhibited 50\% capacity retention after 240 cycles when tested as an anode material for PIBs. Recently, Zhang et al. reported the use of nitrogendoped, defect-rich graphitic nanocarbons for PIBs. The nitrogen rich structures demonstrated stabilized high capacity of $189 \mathrm{mAh} \mathrm{g}^{-1}$ with a long cycle life of 200 cycles at a current density of $200 \mathrm{~mA} \mathrm{~g}^{-1}$. $^{14}$ Similarly, Cao et al. reported graphitic carbon nanocages synthesized from Ketjen carbon black at $2800{ }^{\circ} \mathrm{C}$ under an $\mathrm{Ar}$ atmosphere, ${ }^{19}$ which can sustain a charge capacity of $175 \mathrm{mAh} \mathrm{g}^{-1}$ at $35 \mathrm{C}$ with excellent cyclability. Though improvement of the stability for graphite material in PIBs has been partly achieved by structural modulation, the results are still not satisfactory and far from practical application. In addition, the tedious and complex preparation process seriously impairs the advantage of low cost of graphitic carbon materials. In this regard, we proposed a simple one-pot, self-template, and self-graphitization approach to produce structurally stable hollow graphitized carbon nanocages (HGCNs) as efficient anode materials for PIBs. The HGCNs were prepared by simple pyrolysis of nickel citrate at a relatively low temperature $\left(800-1200{ }^{\circ} \mathrm{C}\right)$ where in situ reduced nickel nanoparticles function together as a hard template to form carbon cage and a catalyst to facilitate the graphitization of carbon-walls. Different from previously reported carbon nanocages, ${ }^{19,20}$ the present strategy is more simple and energy-efficient, as the graphitization can be accomplished at a moderate temperature with the assistance of the in situ reduced nickel nanoparticles as graphitization catalyst. The hollow structure and graphitized carbon-shell endow the HGCNs obtained at $1000{ }^{\circ} \mathrm{C}$ (HGCN-1000) a high initial reversible K-storage capacity of $402.2 \mathrm{mAh} \mathrm{g}^{-1}$ at the current density of $30 \mathrm{~mA} \mathrm{~g}^{-1}$, with maintained reversible capacity of $309.1 \mathrm{mAh} \mathrm{g}^{-1}$ at $50 \mathrm{~mA} \mathrm{~g}$ over 500 cycles. A long cycle life with the steady capacity of $160.5 \mathrm{mAh} \mathrm{g}^{-1}$ in the duration of 2000 cycles was obtained at $1 \mathrm{~A} \mathrm{~g}^{-1}$. The experimental evidence are suggestive that the proposed onepot, self-template, and self-graphitization approach is an efficient route to obtain structurally stable graphitized carbon-nanocages with high applicability as anodes for PIBs.

\section{RESULTS AND DISCUSSION}

The synthesis strategy for HGCNs is schematically illustrated in Figure 1a. The high-temperature carbonization of nickel citrate primarily results in the formation of interconnected carbon spheres where in situ reduced nickel-metal nanoparticles fill the central-core position (Figure $1 \mathrm{~b}$ ). The Ni core plays a crucial role both as hard template and catalyst to modulate the structure and improve the graphitization of carbon-layers in the HGCNs. After removing the nickel-core by washing the pyrolysis products with diluted hydrochloric acid, a hollow-nanocage like morphology was obtained, as shown in Figure S1 and Figure 1c. Here, HGCNs were prepared at different pyrolysis temperatures of $800{ }^{\circ} \mathrm{C}$ (HGCN-800), $1000{ }^{\circ} \mathrm{C}$ (HGCN-1000), and $1200{ }^{\circ} \mathrm{C}$ (HGCN-1200). Figure $1 \mathrm{c}-\mathrm{f}$ shows the corresponding highresolution transmission electron microscopy (HRTEM) images of HGCNs. As expected, the hollow cagelike morphology was evident at all temperatures, with an inner diameter of carbon cage in range of 7-9 $\mathrm{nm}$ and shell thickness of 2-6 nm. As visible from the HRTEM images (Figure $1 \mathrm{~d}-\mathrm{f}$ ), the presence of nickel core has significantly influenced the degree of graphitization with inner walls more graphitic compared to the outer walls in each of the HGCNs. This justifies the capability of in situ reduced Ni nanoparticles to facilitate graphitization of the carbon layers. This catalytic graphitization effect was more dominated at higher temperatures $\left(1200{ }^{\circ} \mathrm{C}\right)$, where an increased number of graphitized carbon layers and more ordered graphite crystalline were obtained compared to the HGCNs prepared at a lower temperature (Figure 1e). To further confirm the role of $\mathrm{Ni}$ nanoparticles in cage-formation and graphitization, the competitive reference sample (NC-1000) was prepared by two-step carbonization: carbonizing the nickel citrate sample at $400{ }^{\circ} \mathrm{C}$, removing the $\mathrm{Ni}$ nanoparticles, and then further carbonizing at $1000{ }^{\circ} \mathrm{C}$. Contrary to the HGCNs, the NC1000 shows a typical hard carbon type morphology with no evidence of mesopores and graphitization (Figure $1 \mathrm{~g}$ ). This confirms the essential role of in situ reduced Ni nanoparticles as both hard template and graphitization catalyst in producing a 3D network of graphitized porous carbon structures.

To obtain further structural insights, the pyrolysis of nickel citrate was studied by thermogravimetric (TG) and Fourier transform infrared (FTIR) spectroscopy analysis. Figure 2a,b shows the TG-curve recorded for the pyrolysis of nickel citrate at $1000{ }^{\circ} \mathrm{C}$ and the corresponding FTIR spectra measured at different weight-loss temperatures. The initial weight loss of $\sim 22.1 \%$ was observed in the temperature range of $100-153$ ${ }^{\circ} \mathrm{C}$. This loss is attributed to the removal of crystalliferous water molecules, as no characteristics absorption peaks of free carboxyl and hydroxyl groups (1145.5, 1278.9, $1718.6 \mathrm{~cm}^{-1}$ ) could be observed in the corresponding FTIR spectrum. The second weight loss of $\sim 19.6 \%$ was observed between 153 and $338{ }^{\circ} \mathrm{C}$, indicating the removal of $\mathrm{C}-\mathrm{O}$ functional groups, as the FTIR spectra confirms the disappearance of the corresponding $\sim 1062 \mathrm{~cm}^{-1}$ absorption peak. An $\sim 30 \%$ weight loss was observed between 347 and $383{ }^{\circ} \mathrm{C}$. This step indicates the complete transformation of nickel citrate into carbon and in situ reduced $\mathrm{Ni}$ nanoparticles besides the elimination of small molecular substances such as $\mathrm{CO}_{2}$ and $\mathrm{H}_{2} \mathrm{O}$ as evident from the weak FTIR symmetric and antisymmetric vibration peaks of $-\mathrm{OH}$ and $-\mathrm{C}=\mathrm{O}$ at 1409 and $1598 \mathrm{~cm}^{-1}$, respectively. $^{21}$ Once the temperature rises above $400{ }^{\circ} \mathrm{C}$, no 

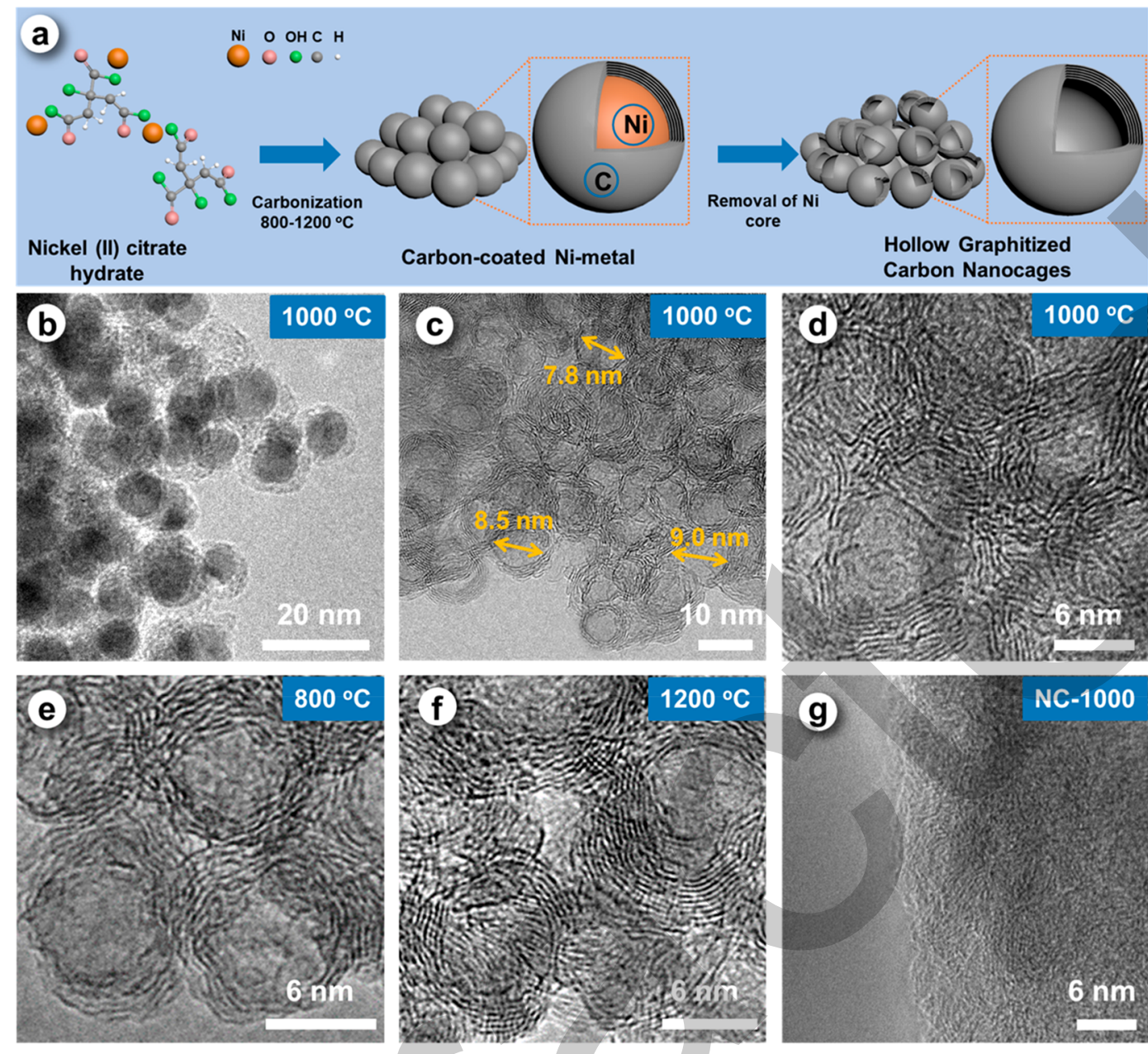

Figure 1. (a) Schematic illustration depicting direct pyrolysis of nickel citrate to form nickel centered carbon spheres and hollow graphitized carbon nanocages (HGCNs) formed after the removal of Ni-metal. TEM images of (b) Ni-centered carbon spheres pyrolysis at $1000{ }^{\circ} \mathrm{C}$ and (c) its hollow-cage counterpart after the removal of Ni metal. (d-f) High-resolution TEM images for HGCNs formed at the pyrolysis temperature of $1000{ }^{\circ} \mathrm{C}(\mathrm{HGCN}-1000), 800{ }^{\circ} \mathrm{C}(\mathrm{HGCN}-800)$, and $1200{ }^{\circ} \mathrm{C}$ (HGCN-1200), respectively. (g) TEM image captured for NC1000.

significant weight loss was observed, confirming the completion of the pyrolysis process.

Figure $2 \mathrm{c}$ shows the X-ray diffraction (XRD) patterns of HGCNs synthesized under different temperatures in reference to the uncatalyzed carbon sample (NC-1000). NC-1000 presents two broad diffraction peaks at $\sim 25.1^{\circ}$ and $\sim 43.0^{\circ}$, corresponding to the (002) and (100) planes of graphite, characterizing a typical amorphous carbon. ${ }^{22}$ In contrast, all the HGCNs show a sharp (002) peak, indicating the existence of graphitic crystallinity. A slight upshift in (002) peak was observed with the increase of pyrolysis temperature from 800 to $1200^{\circ} \mathrm{C}$, indicating the change of graphitization degree and interlayer distance. This interlayer distance was then estimated by applying Bragg-law on (002) peaks observed in the HGCNs. ${ }^{23}$ A gradual decrease in the interlayer distance was observed from $3.426 \AA$ for HGCN-800 to $3.417 \AA$ for HGCN1000 and $3.396 \AA$ for HGCN-1200, confirming the increased graphitization. Figure S2 shows the XRD patterns recorded for unwashed pyrolysis products of nickel(II) citrate obtained at 400 and $1000{ }^{\circ} \mathrm{C}$. The presence of typical $\mathrm{Ni}$ metal peaks in conjunction with carbon confirms their coexistence as hybrids. The degree of graphitization for the synthesized HGCNs was further estimated using Raman analysis. The intensity ratio of characteristic $\mathrm{G}$ band to $\mathrm{D}$ bands $\left(I_{\mathrm{G}} / I_{\mathrm{D}}\right)$ centered at $\sim 1588$ $\mathrm{cm}^{-1}$ and $\sim 1348 \mathrm{~cm}^{-1}$ was calculated for each of the HGCNs in reference to the uncatalyzed carbon, i.e., NC-1000. ${ }^{24}$ Figure $2 \mathrm{~d}$ shows the corresponding Raman spectra with an increasingly sharp G-band as the pyrolysis temperature rises from 800 to $1200{ }^{\circ} \mathrm{C}$. Unlike, NC-1000 presented a low $I_{\mathrm{G}} / I_{\mathrm{D}}$ value of 0.886 , which is typical of the disordered carbons. ${ }^{25}$ The HGCNs were estimated to have a relatively higher $I_{\mathrm{G}} / I_{\mathrm{D}}$ ratio, which increases from 1.023 for $\mathrm{HGCN}-800$ to 1.352 for HGCN-1000 and 1.466 for HGCN-1200, supporting improved catalytic graphitization of in situ reduced $\mathrm{Ni}$ nanoparticles at higher temperatures. In addition, the presence of a sharp band near $\sim 2700 \mathrm{~cm}^{-1}$ in the Raman spectra of HGCN1000 and HGCN-1200 further indicates the elimination of dangling-surface functional moieties and formation of bent graphitic-layers at higher temperatures. ${ }^{26,27}$

The $\mathrm{N}_{2}(77 \mathrm{~K})$ adsorption-desorption isotherms were recorded to study the variation of porosity parameter with increased graphitization of HGCNs (Figure 2e). Contrary to NC-1000, which exhibits a type I isotherm with a low pore volume of $0.21 \mathrm{~cm}^{3} \mathrm{~g}^{-1}$, the HGCNs displayed type IV adsorption/desorption isotherms with a wide hysteresis loop in the relative pressure $\left(p / p_{0}\right)$ range of $0.4-1$, indicating the 

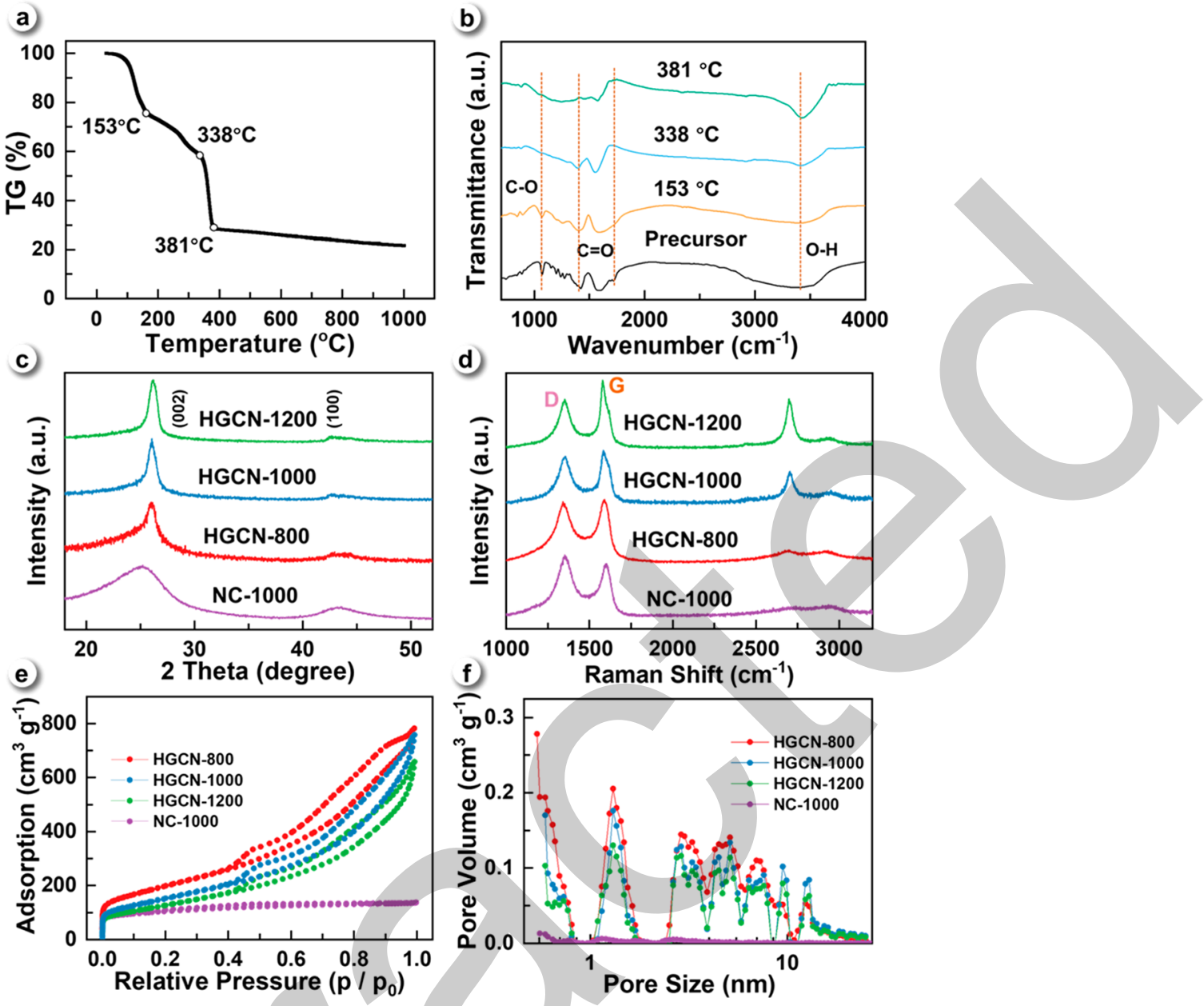

Figure 2. (a) TG curve recorded for the pyrolysis of nickel citrate at $1000{ }^{\circ} \mathrm{C}$ and (b) the corresponding FTIR spectra obtained at different weight-loss temperatures. (c) XRD patterns and (d) Raman spectra of the HGCNs in reference to the uncatalyzed carbon sample (NC1000). (e) Nitrogen adsorption-desorption isotherms and (f) the corresponding DFT pore size distribution curves of HGCNs and NC1000 .

presence of mesopores. ${ }^{28}$ The corresponding density functional theory (DFT) pore size distribution curves are shown as Figure $2 \mathrm{f}$, confirming the average size of mesopores in the range of $2-13 \mathrm{~nm}$. The specific surface area of HGCNs estimated using the Brunauer-Emmett-Teller (BET) method shows a gradual decrement with the rise of pyrolysis temperature. In the case of HGCN-800, the specific surface area was noted to be $685 \mathrm{~m}^{2} \mathrm{~g}^{-1}$ with a pore volume of 1.21 $\mathrm{cm}^{3} \mathrm{~g}^{-1}$ which in the case of HGCN-1000 and HGCN-1200 decreased to $519 \mathrm{~m}^{2} \mathrm{~g}^{-1}\left(1.17 \mathrm{~cm}^{3} \mathrm{~g}^{-1}\right)$ and $433 \mathrm{~m}^{2} \mathrm{~g}^{-1}(1.02$ $\left.\mathrm{cm}^{3} \mathrm{~g}^{-1}\right)$, respectively. This gradual decline could be explained on the basis of increased catalytic-graphitization of $\mathrm{Ni}$ nanoparticles at higher temperatures which permits the carbon layers to arrange in a relatively ordered fashion at the expense of fading mesopores.

Though the structural modulation is a promising route to produce efficient PIB-anodes, the superior electrochemical characteristic including the high reversible capacity, extended cyclability, and rate capability is a synergic outcome of high active surface area, increased porosity, and sufficient graphitization of the anodic material. Thus, a superior electrochemical performance could only be anticipated from the HGCNs which has adequate active site availability in addition to the structural configuration capable of accom- modating large volume changes and shorter $\mathrm{K}$ ion diffusion pathways.

The electrochemical performance of HGCNs as anode material for PIBs was evaluated in CR2025 coin half-cell with potassium as a counter electrode and $0.8 \mathrm{M} \mathrm{KPF}_{6}$ in ethylene carbonate (EC) and polycarbonate (PC) (1:1) mixture as the electrolyte. Figure $3 a-c$ compares the initial three cycles of cyclic voltammetry $(\mathrm{CV})$ curves at a scan rate of $0.1 \mathrm{mV} \mathrm{s}^{-1}$ recorded for $\mathrm{HGCN}-800$, HGCN-1000, and HGCN-1200, respectively. Unlike the NC-1000 (Figure S3a), which shows a typical hard carbon behavior, the HGCNs exhibit reversible $\mathrm{CV}$ profiles consisting of the rectangular-shaped behavior in the potential window of $0.8-3 \mathrm{~V}$ and the wide redox peak in the low-potential region $(0-0.5 \mathrm{~V})$. These two regions correspond to the K-storage mechanism as double-layered capacitive adsorption and the intercalation compounds formed during the insertion/extraction of $\mathrm{K}$ ion within graphitic layers of HGCNs, respectively. As the pyrolysis temperature increases, i.e., HGCN-1200, a significant improvement in the peak shape-characteristics could be observed, which confirms the formation of stabilized intercalation compounds with an increase of graphitization. ${ }^{29}$ The small reduction peak observed at about $0.55 \mathrm{~V}$ in the first reduction process is attributed to the formation of the solid electrolyte interface (SEI) due to the decomposition of the electrolyte, which brings about the 

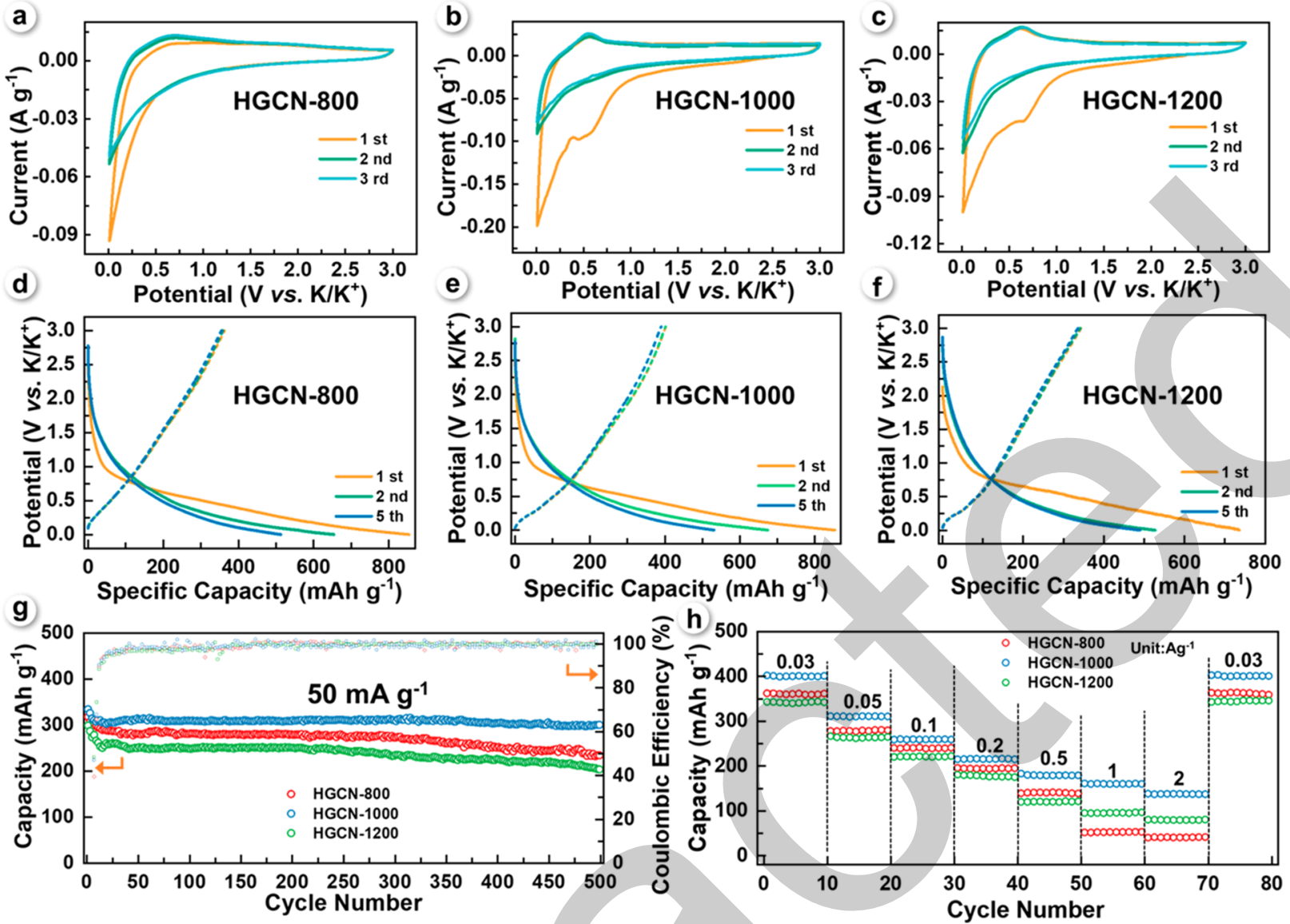

Figure 3. Electrochemical performance of the HGCNs as anodes for PIBs. (a-c) Initial CV cycles for HGCN-800, HGCN-1000, and HGCN1200 recorded at a scan rate of $0.1 \mathrm{mV} \mathrm{s}^{-1},(\mathrm{~d}-\mathrm{f})$ the corresponding charge-discharge profiles at a current density of $30 \mathrm{~mA} \mathrm{~g}^{-1}$, ( $\left.\mathrm{g}\right)$ the competitive cycle performance recorded at the current density of $50 \mathrm{~mA} \mathrm{~g}^{-1}$, and $(\mathrm{h})$ the rate performance of the HGCNs under different current densities in the range of $0.03-2 \mathrm{Ag}^{-1}$.

irreversible capacity loss in the initial charge/discharge process. ${ }^{17,30}$ In the following scans, the CV curves are almost overlapping, indicating excellent electrochemical reversibility of the HGCNs. The galvanostatic charge/discharge curves at a current density of $30 \mathrm{~mA} \mathrm{~g}{ }^{-1}$ for synthesized HGCNs are shown in Figure $3 \mathrm{~d}-\mathrm{f}$. The measured curves are consistent with the redox-behavior observed in the associated CV profile. Unlike the NC-1000, the hollow morphological features of HGCNs possess a much-exposed surface area with additional active sites for $\mathrm{K}$ ion storage, making the $\mathrm{HGCNs}$ prepared at $800-1200{ }^{\circ} \mathrm{C}$ all have dramatic enhanced capacities. As the pyrolysis temperature increases, the enhanced catalyticgraphitization effect of $\mathrm{Ni}$ nanoparticles leads to an improved graphitization degree but decreased porosity as shown in Figure 2, which influence the potassium storage behavior and performance of the HGCNs. HGCN-800 shows a linear charge/discharge profile, indicating surface capacitance contributes a lot to the overall capacity due to the lower graphitization degree and developed porosity with a BET surface area of $685 \mathrm{~m}^{2} \mathrm{~g}^{-1}$. It delivers an initial reversible Kstorage capacity of $362.6 \mathrm{mAh} \mathrm{g}^{-1}$ at a current density of 30 $\mathrm{mA} \mathrm{g}^{-1}$ with an ICE of $42.5 \%$, where the irreversible capacity loss is related to the formation of SEI films on the surface of carbon due to its large surface area. ${ }^{31}$ When the pyrolysis temperature increases to $1000{ }^{\circ} \mathrm{C}$, the enhanced graphitization degree makes the graphitic layers of HGCN-1000 accessible for $\mathrm{K}$ ion insertion/extraction to form stabilized intercalation compounds, which is evidenced by the plateau region in charge/discharge curves as well as the wide redox peak at the low-potential region $(0-0.5 \mathrm{~V})$ of $\mathrm{CV}$ profiles. Due to the cocontribution of surface capacitance and interlayer insertion, HGCN-1000 demonstrates the highest reversible capacity of $402.2 \mathrm{mAh} \mathrm{g}^{-1}$ with an ICE of $47.1 \%$, which is 2.47 -fold higher compared to its nonporous counterpart NC-1000 (162.8 mAh $\mathrm{g}^{-1}$ with an ICE of $45.8 \%$ ). With the temperature increasing to $1200{ }^{\circ} \mathrm{C}$, the reversible K-storage capacity of HGCN-1200 decreases to $343.2 \mathrm{mAh} \mathrm{g}^{-1}$, but the ICE increases to $48.5 \%$, which could be attributed to the much decreased BET surface area $\left(433 \mathrm{~m}^{2} \mathrm{~g}^{-1}\right)$ and defects. Therefore, an optimized pyrolysis temperature is important to balance the interlayer distance and the porosity to get high reversible K-storage capacity.

The competitive cycle performance of HGCNs recorded at $50 \mathrm{~mA} \mathrm{~g}{ }^{-1}(0.18 \mathrm{C})$ is shown in Figure $3 \mathrm{~g}$. Contrary to NC1000 (Figure S4a), which can maintain a low reversible capacity of $118.6 \mathrm{mAh} \mathrm{g}^{-1}$ over 200 cycles, HGCN-1000 endures a high initial reversible capacity of $309.1 \mathrm{mAh} \mathrm{g}^{-1}$ with a capacity retention of $92.4 \%$ during 500 cycles. In addition, the noted columbic efficiency of HGCN-1000 increases rapidly during the initial 10 cycles and then remains above $99 \%$ throughout the measurement period (500 cycles). A similar cycle performance profile was obtained for HGCN-800 and HGCN-1200 with lower reversible capacities of 232.4 and $203.3 \mathrm{mAh} \mathrm{g}^{-1}$, respectively. The excellent cycling stability in 


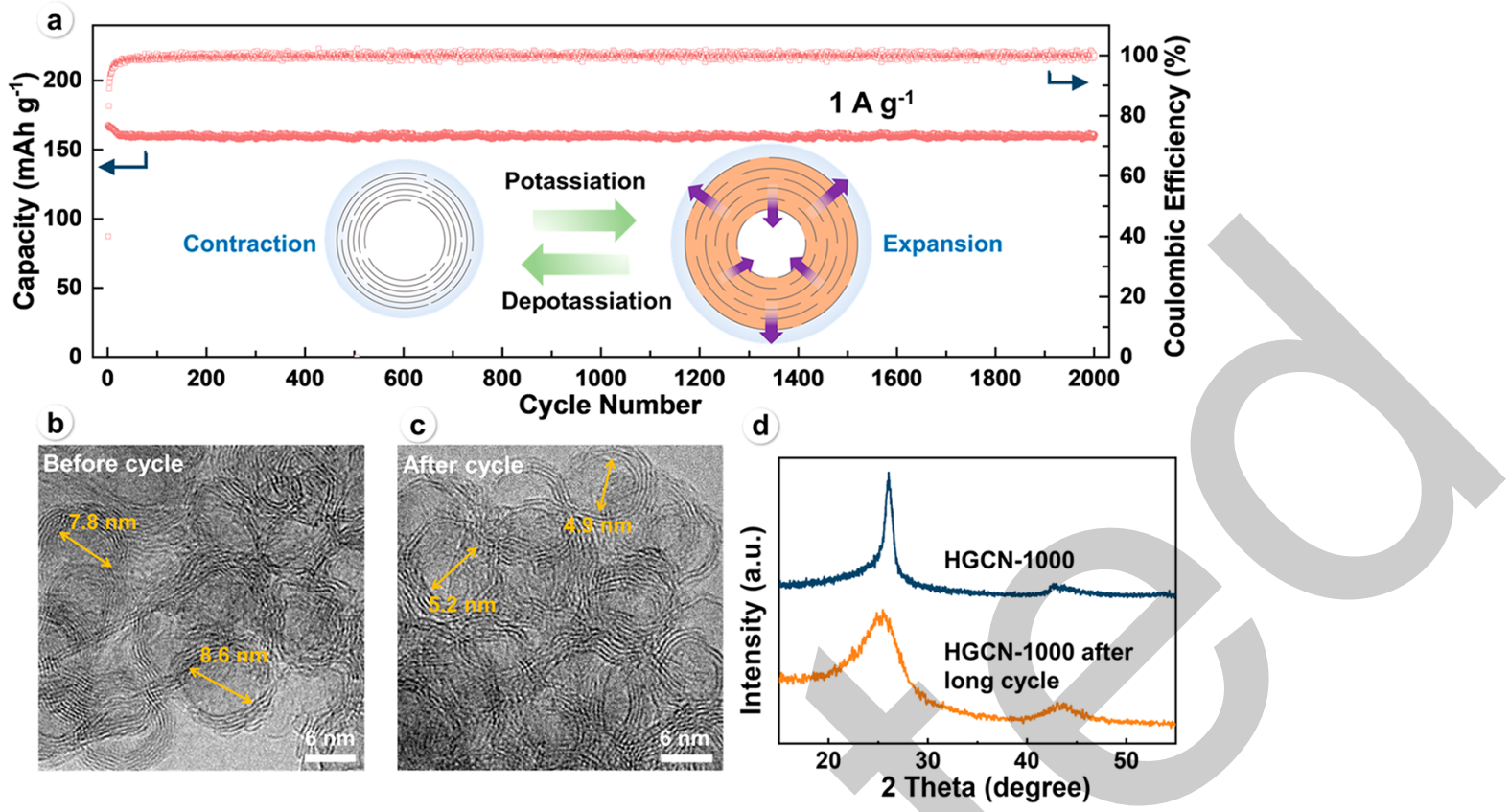

Figure 4. (a) Long cycle performance of HGCN-1000 at a high current density of $1 \mathrm{~A} \mathrm{~g}^{-1}$ over 2000 cycles, with the inset illustration depicting the contraction and expansion of nanocages during insertion/extraction of $\mathrm{K}$ ion. (b,c) The HRTEM images of HGCN-1000 before and after completion of 2000 cycles, and (d) the XRD pattern interpreting the corresponding change of interlayer spacing of HGCN1000 after prolonged cycles.
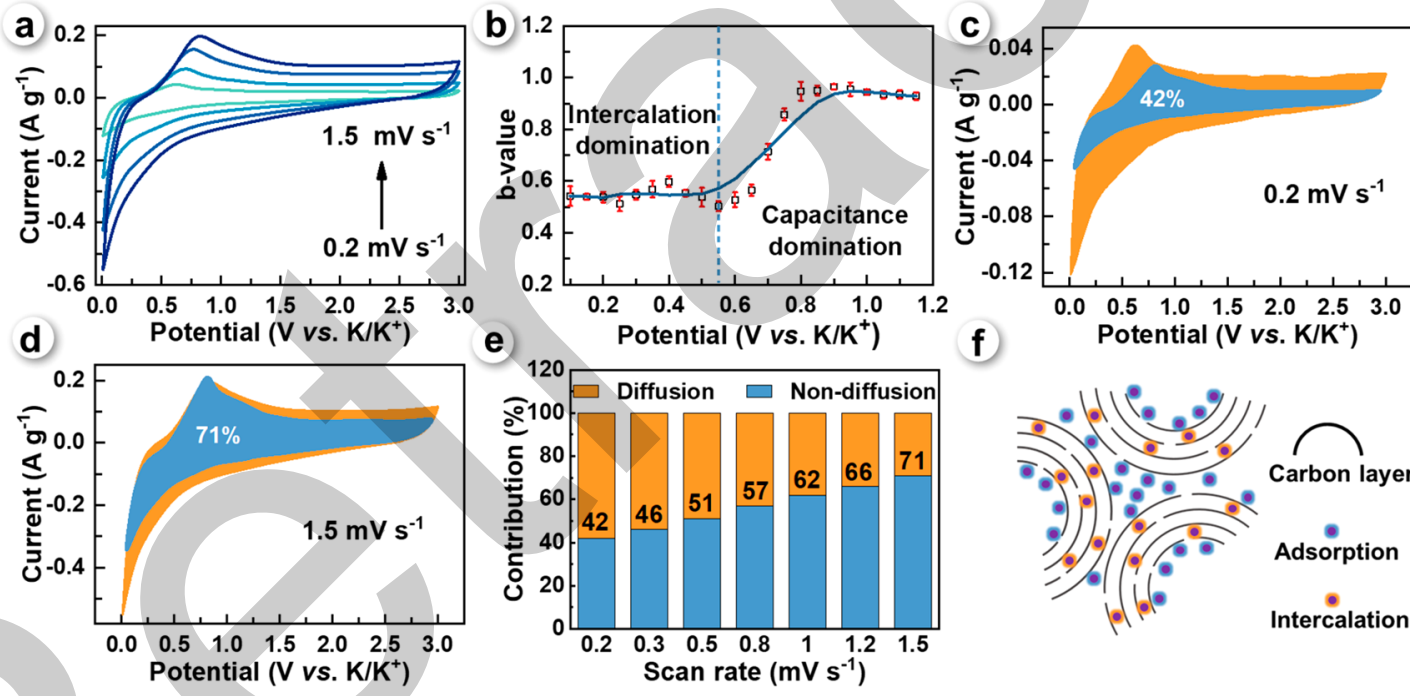

Figure 5. (a) CV profiles for HGCN-1000 measured at different scan rates in the range from 0.2 to $1.5 \mathrm{mV} \mathrm{s}$. (b) Regional variation of capacitance-storage mechanism predicted from the plot of $b$-values against the cathodic potential values. (c,d) The corresponding capacitive contributions variation with rise of scan rate from 0.2 and $1.5 \mathrm{mV} \mathrm{s}^{-1}$. (e) Bar-graph depicting the normalized diffusion and nondiffusion capacitance contribution ratio obtained at different scan rates from $0.2 \mathrm{mV} \mathrm{s}^{-1}$ to $1.5 \mathrm{mV} \mathrm{s}{ }^{-1}$. (f) Schematic illustration showing $\mathrm{K}$ ion storage within graphitized carbon-layers of HGCNs.

the case of HGCNs can be ascribed to the synergic outcome of hollow morphology with graphitized carbon layers configured a stable structure to tolerate large volume deformation during the extended potassium/despotassium cycling. The rate performance of NC-1000 is shown in Figure S4b. As expected, a lower reversible capacity of $162.8 \mathrm{mAh} \mathrm{g}^{-1}$ at $30 \mathrm{~mA} \mathrm{~g}^{-1}$ was obtained for NC-1000 which then rapidly decreases to 29.7 $\mathrm{mAh} \mathrm{g}^{-1}$ as the current density increases to $500 \mathrm{~mA} \mathrm{~g}^{-1}$. In contrast, the HGCNs demonstrate superior rate performance with a much slower decline of reversible capacities as current density increases (Figure 3h). Among all, the HGCN-1000 exhibits the superior rate performance with a high reversible capacity of $402.2 \mathrm{mAh} \mathrm{g}^{-1}$ at $30 \mathrm{~mA} \mathrm{~g}^{-1}$, which can maintain 311.6, 260.4, 216.6, 183.4 $\mathrm{mAh} \mathrm{g}^{-1}$ when the current density increases to $50,100,200$, and $500 \mathrm{~mA} \mathrm{~g}^{-1}$, respectively. The excellent structural characteristics of HGCN-1000 further allowed the constructed anode to retain a reversible capacity of $138.6 \mathrm{mAh} \mathrm{g}^{-1}$ at the high current density of $2 \mathrm{~A} \mathrm{~g}^{-1}(7.2 \mathrm{C})$. The capability of HCGN-1000 to endure high structural deformation was further evaluated by measuring its cycle stability at a current density of $1 \mathrm{~A} \mathrm{~g}^{-1}$ for 2000 long-cycles. As shown in Figure 4a, the HGCN-1000 can maintain a K-storage 
capacity of $160.5 \mathrm{mAh} \mathrm{g}^{-1}$ with $95.9 \%$ retention rate even after 2000 cycles of measurements. Furthermore, ex situ XRD pattern analysis was performed to investigate the interlayer spacing variation of HGCN-1000 after the potassiation and depotassiation process. As shown in Figure S5, the interlayer distance of HGCN-1000 calculated by the Bragg formula based on the (002) peak is $3.42 \AA$, which increases to $3.83 \AA$ after full potassiation and returns back to $3.45 \AA$ after depotassiation, indicating the excellent structural reversibility of HGCNs during the charge/discharge process. ${ }^{31}$ The inset of Figure $4 a$ illustrates the hollow carbon cages' (HGCN-1000) capability to maintain structural integrity during continuous potassiation/depotassiation. Table S1 compares the performance of HGCN-1000 with other recently reported carbon anodes for PIBs. As seen, the HGCN-1000 has relatively superior performance from the view of capacity, cycle, and rate performance in comparison to the other carbon-driven anodes with the merit of structural integrity. ${ }^{19}$ Combining the advantages of the simple process and low energy-consumption, the present strategy is very promising for the synthesis of advanced anodes for PIBs.

HRTEM analysis was later carried to distinguish the structural changes of HGCN-1000 before and after 2000 cycles of measurement. As seen in Figure 4c, HGCN-1000 maintained its inherent cagelike features even after 2000 prolonged cycling. In comparison to the uncycled sample, a decrease in cavity diameter was noted from $\sim 8 \mathrm{~nm}$ to $\sim 5 \mathrm{~nm}$, signifying the essential role of the porous cavity in buffering the large volume expansion. The interlayer spacing of cycled HGCN-1000 was further confirmed by the XRD (Figure 4d) and selected area electron diffraction (SAED) (Figure S6). As expected, a trivial increase in interlayer spacing was noted from 3.41 to $3.51 \AA$, after 2000 cycles of measurement. Unlike the conventional graphite and soft carbon which are known for their deteriorated cycle performance after prolonged cycles, ${ }^{10,14,16,32-44}$ the cagelike morphology in HGCN-1000 provides a concentric carbon-layer arrangement with relatively low anisotropy, which makes interlayer slippage difficult and thereby stimulating high flexibility in the structure without compromising its inherent stability. ${ }^{45-48}$

The electrochemical K-storage mechanisms of HGCNs were investigated by kinetics analysis based on $\mathrm{CV}$ techniques. ${ }^{45}$ Figure 5a shows the $\mathrm{CV}$ profiles of $\mathrm{HGCN}-1000$ recorded at different scan rates in the range from 0.2 to $1.5 \mathrm{mV} \mathrm{s}^{-1}$. The presence of redox peak in a lower-voltage region with a typical rectangle in the higher potential region supports the possibility of two working mechanisms, i.e., surface/defect adsorption and interlayer insertion (Figure 5f), respectively. ${ }^{46}$ To reveal the possible mechanism, the peak current $(i)$ was plotted against the scan rates $(v)$ using the following power-law relationship:

$$
i=a v^{b}
$$

Here, $b$ could be estimated from the slope of the plot of log $(i)$ $v s \log (v) .^{47-49}$ In general, the $b$ value of 0.5 corresponds to an ideal diffusion-controlled process, such as intercalation, whereas the $b$ value of 1.0 depicts a surface-controlled reactions, such as adsorption. ${ }^{50}$ Figure $5 \mathrm{~b}$ shows the scatter plot for the estimated $b$ values against the scan rates used in the $\mathrm{CV}$ profile (Figure 5a). As projected, the two mechanisms are working simultaneously with the surface-controlled process dominant at the higher voltage region $(0.75 \mathrm{~V})$ and the intercalation reaction in the lower voltage region $(0-0.5 \mathrm{~V})$, respectively. The current contribution from these two mechanisms was estimated using the following equations:

$$
i(\mathrm{~V})=k_{1} v+k_{2} v^{1 / 2}
$$

Here $k_{1}$ and $k_{2}$ are constants, $i$ is the current (A) at a fixed potential, and $v$ is the scan rate $\left(\mathrm{mV} \mathrm{s}^{-1}\right)$. A plot of $I(\mathrm{~V}) / v^{1 / 2}$ against $v^{1 / 2}$ is shown in Figure S7 with $k_{1}$ and $k_{2}$ values estimated from the corresponding slope and the intercept. Figure $5 \mathrm{c}-\mathrm{e}$ presents the quantitative current contribution of HGCN-1000 at different scan rates, i.e., 0.2 and $1.5 \mathrm{mV} \mathrm{s}^{-1}$ with blue and yellow regions indicating the capacitance contribution from the nondiffusion and diffusion-controlled electrode processes. As evident, capacitive-controlled current rises from $42 \%$ to $71 \%$ as the scan rate rises from $0.2 \mathrm{mV} \mathrm{s}^{-1}$ to $1.5 \mathrm{mV} \mathrm{s}^{-1}$. The CV profiles of HGCN-800 and HGCN-1200 recorded at different scan rates and the quantitative current contributions at $0.2 \mathrm{mV} \mathrm{s}^{-1}$ and $1.5 \mathrm{mV} \mathrm{s}^{-1}$ were also measured, and the results are shown in Figure S8. Due to the more developed porous structure, HGCN-800 demonstrates a more capacitive-controlled contribution. Its capacitive-controlled current rises from $45 \%$ to $80 \%$, as the scan rate rises from $0.2 \mathrm{mV} \mathrm{s}^{-1}$ to $1.5 \mathrm{mV} \mathrm{s}^{-1}$. For HGCN-1200 with a higher graphitization degree and much decreased porosity, less capacitive-controlled contribution is exhibited, and the corresponding current rises from $30 \%$ to $58 \%$ as the scan rate rises from $0.2 \mathrm{mV} \mathrm{s}^{-1}$ to $1.5 \mathrm{mV} \mathrm{s}^{-1}$. This confirms that the nondiffusion-limited $\mathrm{K}$-storage mechanism is a predominant mechanism which enables HGCNs to bear faster charge/ discharge and excellent rate capability. In general, the evaluated competitive performance, justifying the HGCNs' potential to serve as prospective anode materials for PIBs.

\section{CONCLUSIONS}

In conclusion, we describe a simple yet efficient approach to produce hollow graphitic carbon nanocages (HGCNs) as an advanced anode material for potassium-ion batteries (PIBs). The HGCNs were prepared using a one-pot, self-template and self-graphitization approach where nickel citrate was directly pyrolyzed at high temperatures to convert citrate chains into a carbon-shell and simultaneously reduce $\mathrm{Ni}^{2+}$ (in situ) to form the $\mathrm{Ni}$ nanoparticles core. This $\mathrm{Ni}$ core primarily serves as a catalyst and hard-template to facilitate the graphitization of the formed carbon layers and regulate the structure of the cage, respectively. A competitive electrochemical performance was measured for HGCNs prepared at different pyrolysis temperatures in reference to its hard carbon counterpart. Among all, the HGCNs prepared at the pyrolysis temperature of $1000{ }^{\circ} \mathrm{C}$ (HGCN-1000), based on optimum structural graphitization and porosity and favorable carbon-layer arrangement demonstrated a high K-storage capacity of $402.2 \mathrm{mAh} \mathrm{g}^{-1}$ at the current density of $30 \mathrm{~mA} \mathrm{~g}$. The synergy of the hollow cagelike morphology, with sufficiently graphitized carbon layers, further enabled HGCN-1000 to maintain high cycle stability with a capacity retention of $95.9 \%$ over 2000 cycles at $1 \mathrm{~A} \mathrm{~g}^{-1}$. Moreover, extraordinary rate performance was obtained with a reversible K-storage capacity of $138.6 \mathrm{mAh}$ $\mathrm{g}^{-1}$ at $2 \mathrm{~A} \mathrm{~g}^{-1}$. The proposed approach provides an efficient route to combat the bottleneck issue of cycling instability of graphite materials in PIBs with structurally engineered HGCNs as perspective anode materials with high endurance against volumetric expansion. 


\section{EXPERIMENTAL SECTION}

Materials Synthesis. The hollow graphitized carbon nanocages (HGCNs) were prepared by direct pyrolysis of nickel(II) citrate hydrate $\left(\mathrm{Ni}_{3}\left(\mathrm{C}_{6} \mathrm{H}_{8} \mathrm{O}_{7}\right)_{2} \cdot x \mathrm{H}_{2} \mathrm{O}\right)$ under $\mathrm{N}_{2}$ atmosphere. In a typical procedure, $10 \mathrm{~g}$ of nickel(II) citrate hydrate powder was pyrolyzed at different temperatures of 800,1000 , and $1200{ }^{\circ} \mathrm{C}$ for $3 \mathrm{~h}$ with a ramp temperature of $5{ }^{\circ} \mathrm{C} \min ^{-1}$ after bubbling $\mathrm{N}_{2}$ (99.99\%) into the tubular furnace using a flow rate of $300 \mathrm{sccm} \mathrm{min}^{-1}$. The pyrolyzed products were washed with diluted acid $(3 \mathrm{M} \mathrm{HCl})$ followed by distilled water to remove the $\mathrm{Ni}$ core metal particle. The carbons obtained at different pyrolysis temperatures $(T)$ were denoted as HGCN-T. A carbon-counterpart was prepared by two-step carbonization. Typically, $10 \mathrm{~g}$ of nickel(II) citrate hydrate powder was pyrolyzed in a tubular furnace at $400{ }^{\circ} \mathrm{C}$ for $3 \mathrm{~h}$ with a ramp of $5{ }^{\circ} \mathrm{C}$ $\mathrm{min}^{-1}$ in a $\mathrm{N}_{2}$ atmosphere to get the intermediate product. After washed with $3 \mathrm{M} \mathrm{HCl}$ to remove the $\mathrm{Ni}$ particle and then further heated at $1000{ }^{\circ} \mathrm{C}$ for $3 \mathrm{~h}$ at a ramp of $5{ }^{\circ} \mathrm{C} \mathrm{min}^{-1}$ in $\mathrm{N}_{2}$ atmosphere, the carbon counterpart labeled as $\mathrm{NC}-1000$ was obtained.

Materials Characterization. The morphological characterization of HGCNs was obtained by SEM (Hitachi S4800) and HRTEM (JEOL-2010) observation. The structural characteristics were obtained using Raman spectroscopy (Renishaw inVia Reflex using $514 \mathrm{~nm}$ laser excitation) and XRD analysis using a Bruker AXS D8 with $\mathrm{Cu} \mathrm{K} \alpha$ radiation with a scan speed of $5^{\circ} \mathrm{min}^{-1}$. The nitrogen $(77$ $\mathrm{K})$ adsorption/desorption isotherms were measured at Micromeritics ASAP 2460. The samples were outgassed at $250{ }^{\circ} \mathrm{C}$ for $10 \mathrm{~h}$ under vacuum before testing. The specific surface area was calculated using the conventional BET method, and the pore size distribution was obtained using the DFT approach based on the nitrogen adsorption data. TG (Mettler Toledo) measurement was conducted to analyze the pyrolysis behavior of nickel citrate under a nitrogen atmosphere for the specific pyrolysis temperature of $1000{ }^{\circ} \mathrm{C}$ at $5{ }^{\circ} \mathrm{C} \mathrm{min}{ }^{-1}$, with FTIR measurements conducted at each weight loss stage using a Nicolet iS10 spectrometer (Thermo Electron Corp.).

Electrochemical Measurements. All the electrochemical tests were conducted in CR2025 coin half-cells. The electrodes were fabricated by depositing a mixture of active material, Super P, and CMC binder with a weight ratio of $8: 1: 1$ onto the $\mathrm{Cu}$ foil, followed by drying at $120^{\circ} \mathrm{C}$ for $12 \mathrm{~h}$ under vacuum conditions. The as-prepared electrodes with a mass loading of $\sim 1.2 \mathrm{mg} \mathrm{cm}^{-2}$ were cut into round slices of $10 \mathrm{~mm}$ in diameter and then used as the working electrode. Coin cells were assembled in an argon-filled glovebox (Mikrouna) with water and oxygen contents kept less than $0.1 \mathrm{ppm}$ with a glass fiber as the separator, potassium metal as the counter electrode, and $0.8 \mathrm{M} \mathrm{KPF}_{6}$ within a mixture of ethylene carbonate (EC) and polycarbonate (PC) (1:1 by volume) as electrolyte. The galvanostatic charge/discharge measurements were performed using a Land BT2000 battery tester (Wuhan, China) with a potential window of $0.001-3 \mathrm{~V}$. The cyclic voltammetry profiles were collected on a VSP Bio-Logic SAS workstation at a scan rate of $0.1 \mathrm{mV} \mathrm{s}^{-1}$.

\section{ASSOCIATED CONTENT}

\section{(s) Supporting Information}

The Supporting Information is available free of charge at https://pubs.acs.org/doi/10.1021/acsnano.0c01150.

SEM images of HGCN-1000; XRD patterns of the unwashed pyrolyzed product from nickel(II) citrate hydrate at 400 and $1000{ }^{\circ} \mathrm{C}$; electrochemical K-storage performance of uncatalyzed carbon counterpart of HGCNs (NC-1000); long-cycle performance and rate capability of NC-1000; interlayer spacing variation of HGCN-1000 electrode during the potassiation and depotassiation processes; SAED patterns for uncycled and cycled HGCN-1000 electrodes; plot of $i(\mathrm{~V}) / v^{1 / 2}$ against $v^{1 / 2}$ at different potentials with corresponding slopes values to estimate $k_{1}$ and $k_{2}$ constants for HGCN1000; CV profiles measured at different scan rates and the corresponding capacitive contributions varying with scan rate for HGCN-800 and HGCN-1200; and comparison of the electrochemical performance of HGCNs with competitive materials utilized as anodes for PIBs (PDF)

\section{AUTHOR INFORMATION}

\section{Corresponding Author}

Bin Xu - State Key Laboratory of Organic-Inorganic Composites, Beijing Key Laboratory of Electrochemical Process and Technology for Materials, Beijing University of Chemical Technology, Beijing 100029, P. R. China; orcid.org/00000001-5177-8929; Email: binxumail@163.com, xubin@ mail.buct.edu.cn

\section{Authors}

Zhanpeng Li - State Key Laboratory of Organic-Inorganic Composites, Beijing Key Laboratory of Electrochemical Process and Technology for Materials, Beijing University of Chemical Technology, Beijing 100029, P. R. China

Ning Sun - State Key Laboratory of Organic-Inorganic Composites, Beijing Key Laboratory of Electrochemical Process and Technology for Materials and Beijing Advanced Innovation Centre for Soft Matter Science and Engineering, Beijing University of Chemical Technology, Beijing 100029, P. R. China

Razium Ali Soomro - State Key Laboratory of Organic-Inorganic Composites, Beijing Key Laboratory of Electrochemical Process and Technology for Materials and Beijing Advanced Innovation Centre for Soft Matter Science and Engineering, Beijing University of Chemical Technology, Beijing 100029, P. R. China

Zhaoruxin Guan - State Key Laboratory of Organic-Inorganic Composites, Beijing Key Laboratory of Electrochemical Process and Technology for Materials, Beijing University of Chemical Technology, Beijing 100029, P. R. China

Li Ma - State Key Laboratory of Organic-Inorganic Composites, Beijing Key Laboratory of Electrochemical Process and Technology for Materials, Beijing University of Chemical Technology, Beijing 100029, P. R. China

Mingchi Jiang - State Key Laboratory of Organic-Inorganic Composites, Beijing Key Laboratory of Electrochemical Process and Technology for Materials, Beijing University of Chemical Technology, Beijing 100029, P. R. China

Qizhen Zhu - State Key Laboratory of Organic-Inorganic Composites, Beijing Key Laboratory of Electrochemical Process and Technology for Materials, Beijing University of Chemical Technology, Beijing 100029, P. R. China

Complete contact information is available at:

https://pubs.acs.org/10.1021/acsnano.0c01150

\section{Author Contributions}

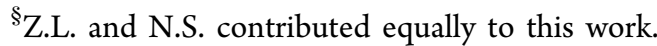

\section{Notes}

The authors declare no competing financial interest.

\section{ACKNOWLEDGMENTS}

This work was financially supported by the National Key R\&D Program of China (Grant No. 2017YFB0102204), the Beijing Municipal Science and Technology Commission (Grant No. Z181100004718007), and the National Natural Science Foundation of China (Grant No. 51572011). The authors 
are thankful to Prof. Yury Gogotsi for valuable discussions and suggestions.

\section{REFERENCES}

(1) Beltrop, K.; Beuker, S.; Heckmann, A.; Winter, M.; Placke, T. Alternative Electrochemical Energy Storage: Potassium-Based DualGraphite Batteries. Energy Environ. Sci. 2017, 10, 2090-2094.

(2) Wu, X.; Leonard, D. P.; Ji, X. Emerging Non-Aqueous Potassium-Ion Batteries: Challenges and Opportunities. Chem. Mater. 2017, 29, 5031-5042.

(3) Jian, Z.; Luo, W.; Ji, X. Carbon Electrodes for K-Ion Batteries. J. Am. Chem. Soc. 2015, 137, 11566-11569.

(4) Wang, W.; Zhou, J.; Wang, Z.; Zhao, L.; Li, P.; Yang, Y.; Yang, C.; Huang, H.; Guo, S. Short-Range Order in Mesoporous Carbon Boosts Potassium-Ion Battery Performance. Adv. Energy Mater. 2018, $8,1701648$.

(5) Sun, N.; Zhu, Q.; Anasori, B.; Zhang, P.; Liu, H.; Gogotsi, Y.; $\mathrm{Xu}$, B. MXene-Bonded Flexible Hard Carbon Film as Anode for Stable Na/K-Ion Storage. Adv. Funct. Mater. 2019, 29, 1906282.

(6) Ding, J.; Zhang, H.; Zhou, H.; Feng, J.; Zheng, X.; Zhong, C.; Paek, E.; Hu, W.; Mitlin, D. Sulfur-Grafted Hollow Carbon Spheres for Potassium-Ion Battery Anodes. Adv. Mater. 2019, 31, No. 1900429.

(7) Gao, H.; Zhou, T.; Zheng, Y.; Zhang, Q.; Liu, Y.; Chen, J.; Liu, H.; Guo, Z. CoS Quantum Dot Nanoclusters for High-Energy Potassium-Ion Batteries. Adv. Funct. Mater. 2017, 27, 1702634.

(8) Ren, X.; Zhao, Q.; McCulloch, W. D.; Wu, Y. $\mathrm{MoS}_{2}$ as a LongLife Host Material for Potassium Ion Intercalation. Nano Res. 2017, 10, 1313-1321.

(9) Sultana, I.; Rahman, M. M.; Mateti, S.; Ahmadabadi, V. G.; Glushenkov, A. M.; Chen, Y. K-Ion and Na-Ion Storage Performances of $\mathrm{Co}_{3} \mathrm{O}_{4}-\mathrm{Fe}_{2} \mathrm{O}_{3}$ Nanoparticle-Decorated Super P Carbon Black Prepared by a Ball Milling Process. Nanoscale 2017, 9, 3646-3654.

(10) Yao, Q.; Zhang, J.; Li, J.; Huang, W.; Hou, K.; Zhao, Y.; Guan, L. Yolk-Shell NiS @ @ Nanosheets as K-Ion Battery Anodes with High Rate Capability and Ultralong Cycle Life. J. Mater. Chem. A 2019, 7, 18932-18939.

(11) Chong, S.; Sun, L.; Shu, C.; Guo, S.; Liu, Y.; Wang, W.; Liu, H. K. Chemical Bonding Boosts Nano-Rose-Like $\mathrm{MoS}_{2}$ Anchored on Reduced Graphene Oxide for Superior Potassium-Ion Storage. Nano Energy 2019, 63, 103868.

(12) Dong, Y.; Wu, Z. S.; Zheng, S.; Wang, X.; Qin, J.; Wang, S.; Shi, $\mathrm{X}$; Bao, X. $\mathrm{Ti}_{3} \mathrm{C}_{2}$ MXene-Derived Sodium/Potassium Titanate Nanoribbons for High-Performance Sodium/Potassium Ion Batteries with Enhanced Capacities. ACS Nano 2017, 11, 4792-4800.

(13) Zeng, C.; Xie, F.; Yang, X.; Jaroniec, M.; Zhang, L.; Qiao, S. Z. Ultrathin Titanate Nanosheets/Graphene Films Derived from Confined Transformation for Excellent $\mathrm{Na} / \mathrm{K}$ Ion Storage. Angew. Chem., Int. Ed. 2018, 57, 8540-8544.

(14) Zhang, W.; Ming, J.; Zhao, W.; Dong, X.; Hedhili, M. N.; Costa, P. M. F. J.; Alshareef, H. N. Graphitic Nanocarbon with Engineered Defects for High-Performance Potassium-Ion Battery Anodes. Adv. Funct. Mater. 2019, 29, 1903641.

(15) Liu, Y.; Dai, H.; Wu, L.; Zhou, W.; He, L.; Wang, W.; Yan, W.; Huang, Q.; Fu, L.; Wu, Y. A Large Scalable and Low-Cost Sulfur/ Nitrogen Dual-Doped Hard Carbon as the Negative Electrode Material for High-Performance Potassium-Ion Batteries. Adv. Energy Mater. 2019, 9, 1901379.

(16) Wu, X.; Chen, Y.; Xing, Z.; Lam, C. W. K.; Pang, S. S.; Zhang, W.; Ju, Z. Advanced Carbon-Based Anodes for Potassium-Ion Batteries. Adv. Energy Mater. 2019, 9, 1900343.

(17) Zhao, J.; Zou, X.; Zhu, Y.; Xu, Y.; Wang, C. Electrochemical Intercalation of Potassium into Graphite. Adv. Funct. Mater. 2016, 26, $8103-8110$

(18) Xing, Z.; Qi, Y.; Jian, Z.; Ji, X. Polynanocrystalline Graphite: A New Carbon Anode with Superior Cycling Performance for K-Ion Batteries. ACS Appl. Mater. Interfaces 2017, 9, 4343-4351.

(19) Cao, B.; Zhang, Q.; Liu, H.; Xu, B.; Zhang, S.; Zhou, T.; Mao, J.; Pang, W. K.; Guo, Z.; Li, A.; Zhou, J.; Chen, X.; Song, H. Graphitic
Carbon Nanocage as a Stable and High Power Anode for PotassiumIon Batteries. Adv. Energy Mater. 2018, 8, 1801149.

(20) Zhang, E.; Wang, B.; Wang, J.; Ding, H.; Zhang, S.; Duan, H.; $\mathrm{Yu}, \mathrm{X}$.; Lu, B. Rapidly Synthesizing Interconnected Carbon Nanocage by Microwave toward High-Performance Aluminum Batteries. Chem. Eng. J. 2020, 389, 124407.

(21) Sevilla, M.; Fuertes, A. B. A General and Facile Synthesis Strategy towards Highly Porous Carbons: Carbonization of Organic Salts. J. Mater. Chem. A 2013, 1, 13738-13741.

(22) Jian, Z.; Xing, Z.; Bommier, C.; Li, Z.; Ji, X. Hard Carbon Microspheres: Potassium-Ion Anode versus Sodium-Ion Anode. Adv. Energy Mater. 2016, 6, 1501874.

(23) Wang, X.; Xu, X.; Niu, C.; Meng, J.; Huang, M.; Liu, X.; Liu, Z.; Mai, L. Earth Abundant Fe/Mn-Based Layered Oxide Interconnected Nanowires for Advanced K-Ion Full Batteries. Nano Lett. 2017, 17, 544-550.

(24) Wang, H.; Abe, T.; Maruyama, S.; Iriyama, Y.; Ogumi, Z.; Yoshikawa, K. Graphitized Carbon Nanobeads with an Onion Texture as a Lithium-Ion Battery Negative Electrode for High-Rate Use. $A d v$. Mater. 2005, 17, 2857-2860.

(25) Sun, N.; Liu, H.; Xu, B. Facile Synthesis of High Performance Hard Carbon Anode Materials for Sodium Ion Batteries. J. Mater. Chem. A 2015, 3, 20560-20566.

(26) Gogotsi, Y. Graphite Polyhedral Crystals. Science 2000, 290, 317-320.

(27) Sun, N.; Guan, Z.; Liu, Y.; Cao, Y.; Zhu, Q.; Liu, H.; Wang, Z.; Zhang, P.; Xu, B. Extended "Adsorption-Insertion" Model: A New Insight into the Sodium Storage Mechanism of Hard Carbons. Adv. Energy Mater. 2019, 9, 1901351.

(28) Yu, S.; Sun, N.; Hu, L.; Wang, L.; Zhu, Q.; Guan, Y.; Xu, B. Self-Template and Self-Activation Synthesis of Nitrogen-Doped Hierarchical Porous Carbon for Supercapacitors. J. Power Sources 2018, 405, 132-141.

(29) Ju, Z.; Zhang, S.; Xing, Z.; Zhuang, Q.; Qiang, Y.; Qian, Y. Direct Synthesis of Few-Layer F-Doped Graphene Foam and Its Lithium/Potassium Storage Properties. ACS Appl. Mater. Interfaces 2016, 8, 20682-20690.

(30) Liu, Y.; Fan, F.; Wang, J.; Liu, Y.; Chen, H.; Jungjohann, K. L.; Xu, Y.; Zhu, Y.; Bigio, D.; Zhu, T.; Wang, C. In Situ Transmission Electron Microscopy Study of Electrochemical Sodiation and Potassiation of Carbon Nanofibers. Nano Lett. 2014, 14, 3445-3452.

(31) Zhang, Z.; Jia, B.; Liu, L.; Zhao, Y.; Wu, H.; Qin, M.; Han, K.; Wang, W. A.; Xi, K.; Zhang, L.; Qi, G.; Qu, X.; Kumar, R. V. Hollow Multihole Carbon Bowls: A Stress-Release Structure Design for HighStability and High-Volumetric-Capacity Potassium-Ion Batteries. ACS Nano 2019, 13, 11363-11371.

(32) Ding, J.; Zhang, H.; Zhou, H.; Feng, J.; Zheng, X.; Zhong, C.; Paek, E.; Hu, W.; Mitlin, D. Sulfur-Grafted Hollow Carbon Spheres for Potassium-Ion Battery Anodes. Adv. Mater. 2019, 31, 1900429.

(33) He, G.; Nazar, L. F. Crystallite Size Control of Prussian White Analogues for Nonaqueous Potassium-Ion Batteries. ACS Energy Lett. 2017, 2, 1122-1127.

(34) Hu, X.; Liu, Y.; Chen, J.; Yi, L.; Zhan, H.; Wen, Z. Fast Redox Kinetics in Bi-Heteroatom Doped 3D Porous Carbon Nanosheets for High-Performance Hybrid Potassium-Ion Battery Capacitors. Adv. Energy Mater. 2019, 9, 1901533.

(35) Li, D.; Cheng, X.; Xu, R.; Wu, Y.; Zhou, X.; Ma, C.; Yu, Y. Manipulation of 2D Carbon Nanoplates with a Core-Shell Structure for High-Performance Potassium-Ion Batteries. J. Mater. Chem. A 2019, 7, 19929-19938.

(36) Liu, S.; Yang, B.; Zhou, J.; Song, H. Nitrogen-Rich CarbonOnion-Constructed Nanosheets: An Ultrafast and Ultrastable Dual Anode Material for Sodium and Potassium Storage. J. Mater. Chem. A 2019, 7, 18499-18509.

(37) Liu, Y.; Dai, H.; Wu, L.; Zhou, W.; He, L.; Wang, W.; Yan, W.; Huang, Q.; Fu, L.; Wu, Y. A Large Scalable and Low-Cost Sulfur/ Nitrogen Dual-Doped Hard Carbon as the Negative Electrode Material for High-Performance Potassium-Ion Batteries. Adv. Energy Mater. 2019, 9, 1901379. 
(38) Lv, C.; Xu, W.; Liu, H.; Zhang, L.; Chen, S.; Yang, X.; Xu, X.; Yang, D. 3D Sulfur and Nitrogen Codoped Carbon Nanofiber Aerogels with Optimized Electronic Structure and Enlarged Interlayer Spacing Boost Potassium-Ion Storage. Small 2019, 15, 1900816.

(39) Qian, Y.; Jiang, S.; Li, Y.; Yi, Z.; Zhou, J.; Li, T.; Han, Y.; Wang, Y.; Tian, J.; Lin, N.; Qian, Y. In Situ Revealing the Electroactivity of P$\mathrm{O}$ and $\mathrm{P}-\mathrm{C}$ Bonds in Hard Carbon for High-Capacity and Long-Life Li/K-Ion Batteries. Adv. Energy Mater. 2019, 9, 1901676.

(40) Qiu, W.; Xiao, H.; Li, Y.; Lu, X.; Tong, Y. Nitrogen and Phosphorus Codoped Vertical Graphene/Carbon Cloth as a BinderFree Anode for Flexible Advanced Potassium Ion Full Batteries. Small 2019, 15, No. 1901285.

(41) Ruan, J.; Wu, X.; Wang, Y.; Zheng, S.; Sun, D.; Song, Y.; Chen, M. Nitrogen-Doped Hollow Carbon Nanospheres towards the Application of Potassium Ion Storage. J. Mater. Chem. A 2019, 7, 19305-19315.

(42) Xia, G.; Wang, C.; Jiang, P.; Lu, J.; Diao, J.; Chen, Q. Nitrogen/ Oxygen Co-Doped Mesoporous Carbon Octahedrons for HighPerformance Potassium-Ion Batteries. J. Mater. Chem. A 2019, 7, 12317-12324.

(43) Zeng, S.; Zhou, X.; Wang, B.; Feng, Y.; Xu, R.; Zhang, H.; Peng, S.; Yu, Y. Freestanding CNT-Modified Graphitic Carbon Foam as a Flexible Anode for Potassium Ion Batteries. J. Mater. Chem. A 2019, 7, 15774-15781.

(44) Zhang, M.; Shoaib, M.; Fei, H.; Wang, T.; Zhong, J.; Fan, L.; Wang, L.; Luo, H.; Tan, S.; Wang, Y.; Zhu, J.; Hu, J.; Lu, B. Hierarchically Porous N-Doped Carbon Fibers as a Free-Standing Anode for High-Capacity Potassium-Based Dual-Ion Battery. Adv. Energy Mater. 2019, 9, 1901663.

(45) Luo, W.; Wan, J.; Ozdemir, B.; Bao, W.; Chen, Y.; Dai, J.; Lin, H.; Xu, Y.; Gu, F.; Barone, V.; Hu, L. Potassium Ion Batteries with Graphitic Materials. Nano Lett. 2015, 15, 7671.

(46) Yang, J.; Ju, Z.; Jiang, Y.; Xing, Z.; Xi, B.; Feng, J.; Xiong, S. Enhanced Capacity and Rate Capability of Nitrogen/Oxygen DualDoped Hard Carbon in Capacitive Potassium-Ion Storage. Adv. Mater. 2018, 30, 1700104.

(47) Lindström, H.; Södergren, S.; Solbrand, A.; Rensmo, H.; Hjelm, J.; Hagfeldt, A.; Lindquist, S. E. $\mathrm{Li}^{+}$Ion Insertion in $\mathrm{TiO}_{2}$ (Anatase). 2. Voltammetry on Nanoporous Films. J. Phys. Chem. B 1997, 101, $7717-7722$.

(48) Wang, J.; Polleux, J.; Lim, J.; Dunn, B. Pseudocapacitive Contributions to Electrochemical Energy Storage in $\mathrm{TiO}_{2}$ (Anatase) Nanoparticles. J. Phys. Chem. C 2007, 111, 14925-14931.

(49) Simon, P.; Gogotsi, Y.; Dunn, B. Where Do Batteries End and Supercapacitors Begin? Science 2014, 343, 1210-1211.

(50) Liu, H.; Jia, M.; Cao, B.; Chen, R.; Lv, X.; Tang, R.; Wu, F.; Xu, B. Nitrogen-Doped Carbon/Graphene Hybrid Anode Material for Sodium-Ion Batteries with Excellent Rate Capability. J. Power Sources 2016, 319, 195-201.
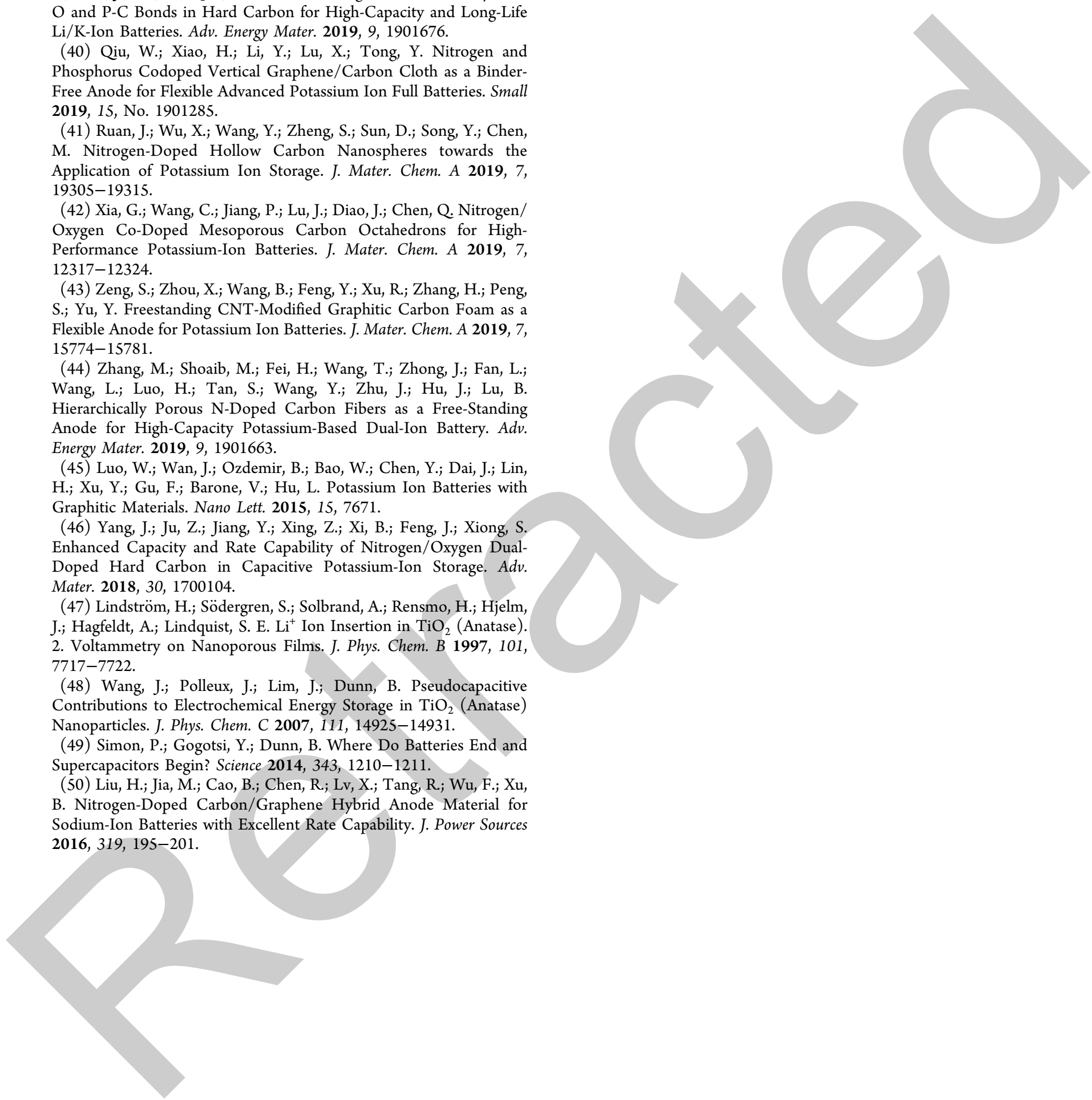


\section{Supporting Information}

\section{Structurally Engineered Hollow Graphitized}

\section{Carbon Nanocages as High-Performance Anodes}

\section{for Potassium Ion Batteries}

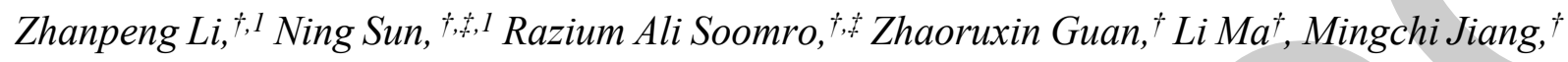
Qizhen $\mathrm{Zhu}^{\dagger}$ and Bin $\mathrm{Xu}{ }^{* \dagger}$

'State Key Laboratory of Organic-Inorganic Composites, Beijing Key Laboratory of Electrochemical Process and Technology for Materials, Beijing University of Chemical Technology, Beijing 100029, P. R. China

E-mail: binxumail@163.com,xubin@mail.buct.edu.cn

Beijing Advanced Innovation Centre for Soft Matter Science and Engineering, Beijing University of Chemical Technology, Beijing, 100029, P. R. China.

${ }^{1}$ Z. L. and N. S. contributed equally to this work. 

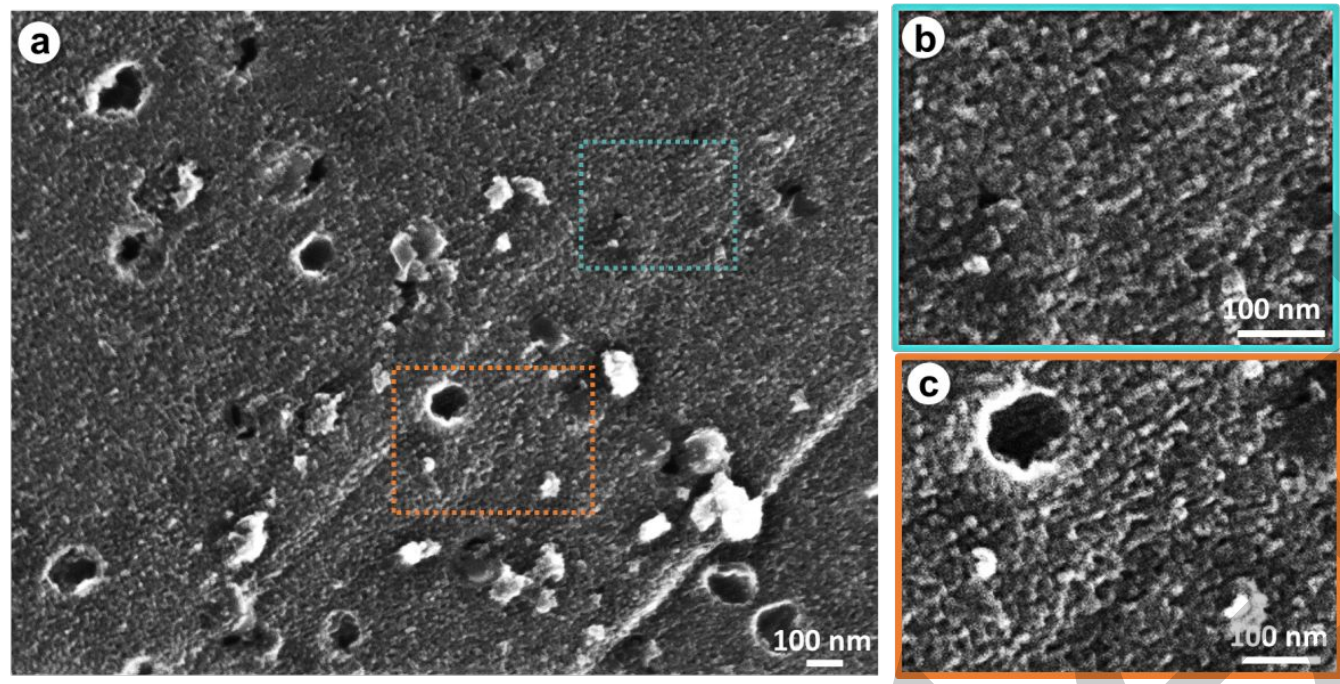

Figure S1 SEM images at different magnifications of HGCN-1000.

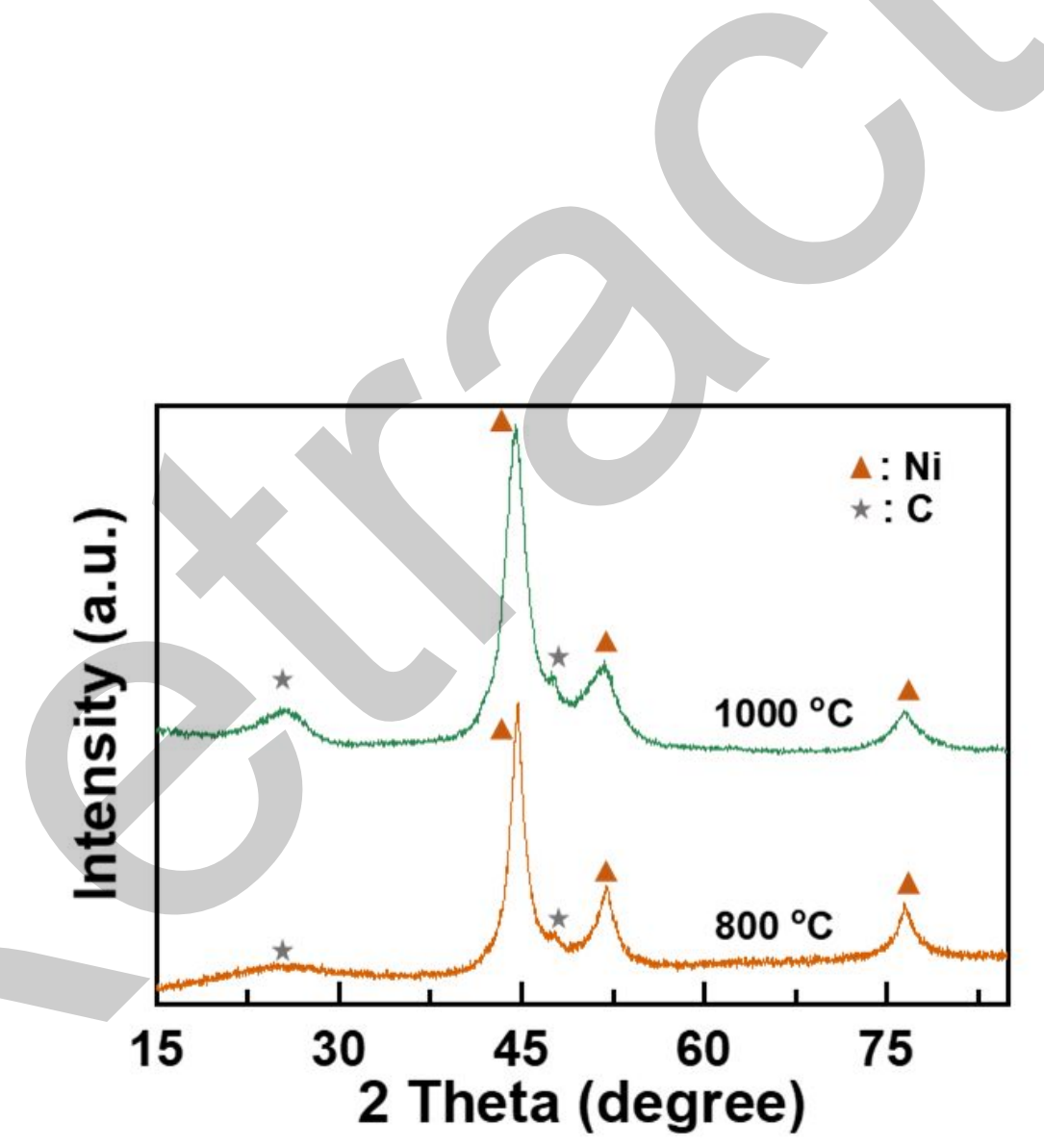

Figure S2 XRD patterns of the un-washed pyrolyzed product from nickel (II) citrate hydrate at $400{ }^{\circ} \mathrm{C}$ and $1000{ }^{\circ} \mathrm{C}$ indicating the presence of typical $\mathrm{Ni}$ and $\mathrm{C}$ peaks. 

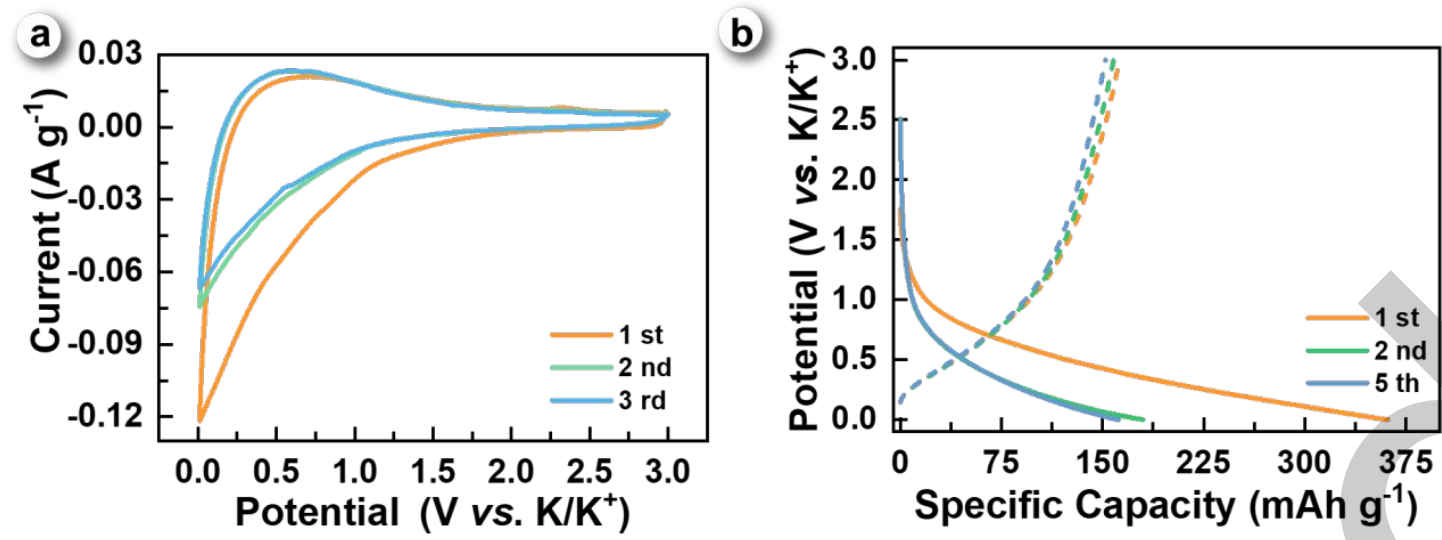

Figure S3 Electrochemical K-storage performance of un-catalyzed carbon counterpart of HGCNs (NC-1000) with (a) showing the CV profile with initial cycles obtained at a scan rate of $0.1 \mathrm{mV} \mathrm{s}^{-1}$ and (b) the corresponding charge-discharge voltage profiles measured at the current density of $30 \mathrm{~mA} \mathrm{~g}^{-1}$.
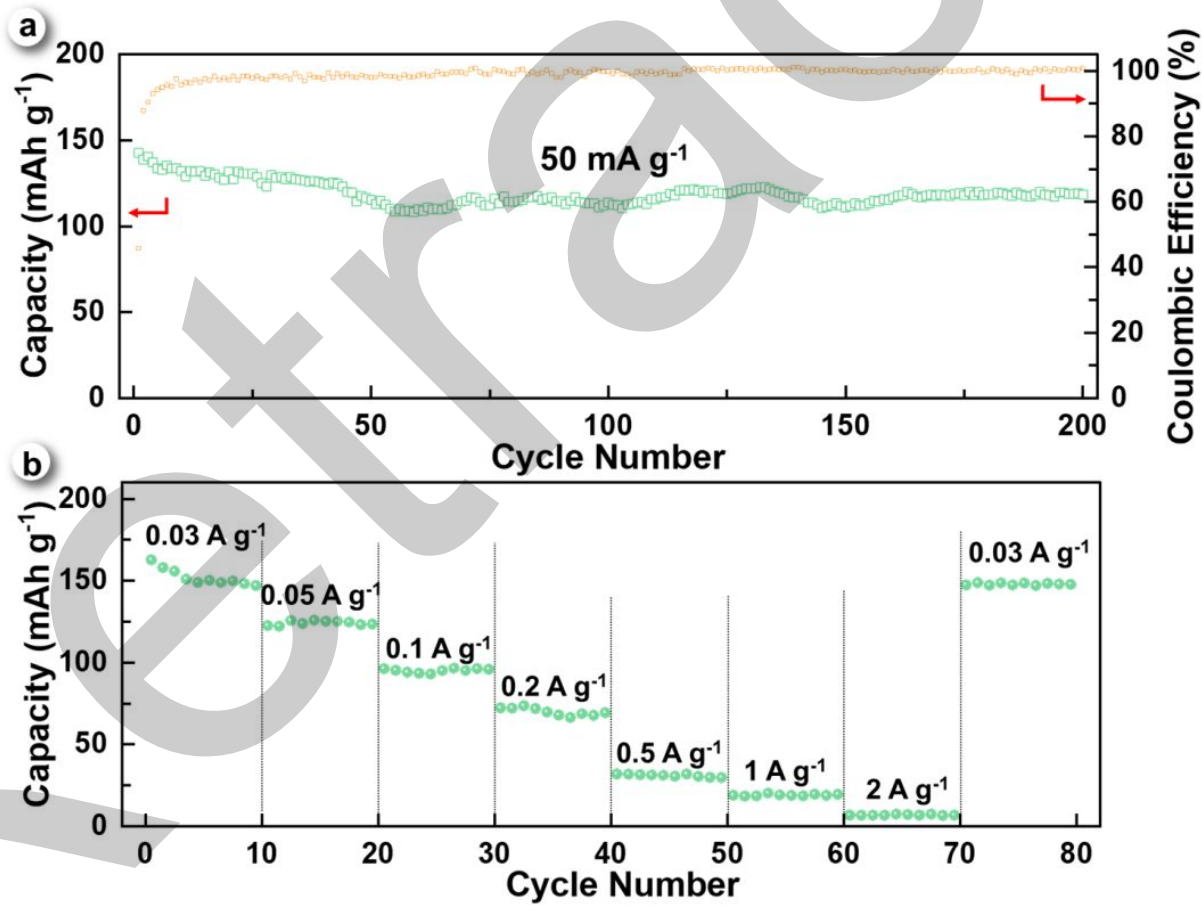

Figure S4 (a) Long-cycle performance measured at $50 \mathrm{~mA} \mathrm{~g}^{-1}$, and (b) rate performance of NC1000 . 

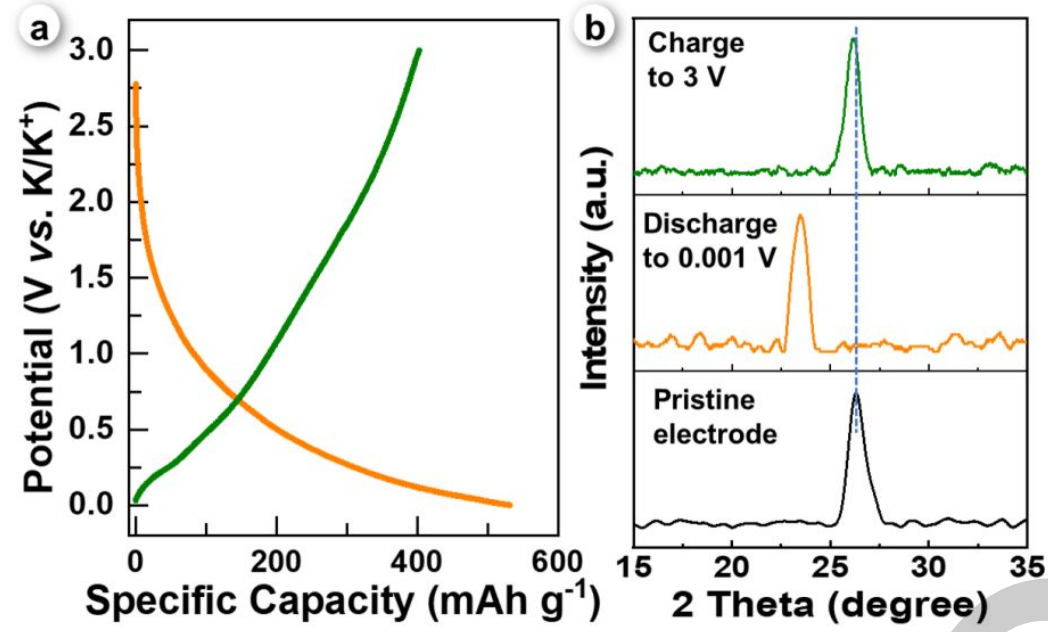

Figure S5 Charge/discharge curves at the current density of $30 \mathrm{~mA} \mathrm{~g}^{-1}$ and ex situ XRD patterns of the HGCN-1000 electrode at different charge/discharge states, indicating the interlayer spacing variation during potassiation and depotassiation process (based on the 3rd charge/discharge cycle).
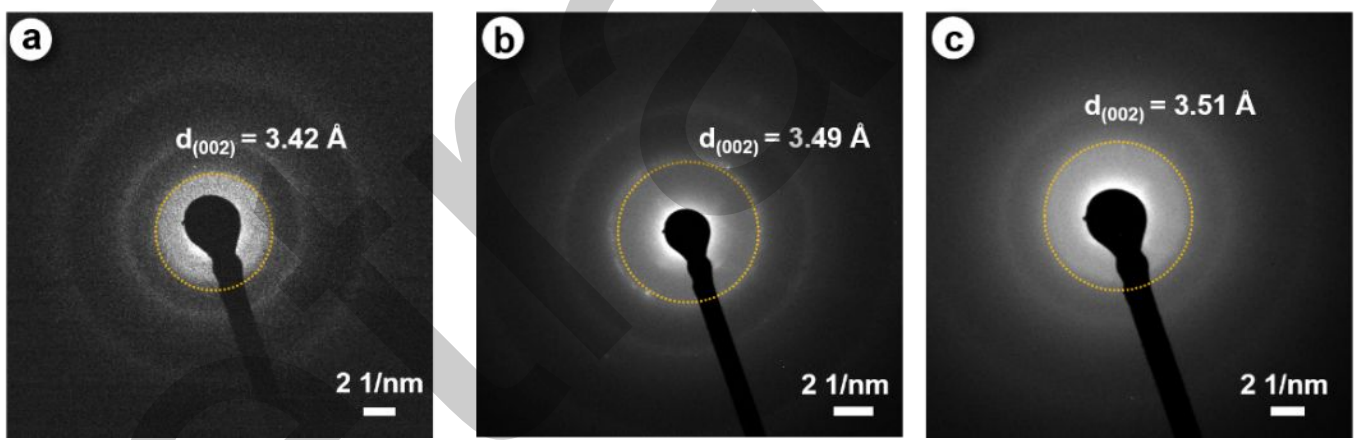

Figure S6 SAED patterns obtained for (a) uncycled HGCN-1000; (b) HGCN-1000 after the first cycle, and (c) after completion of 2000 cycles, indicating a negligible variation in the interlayer spacing of HGCN-1000. 


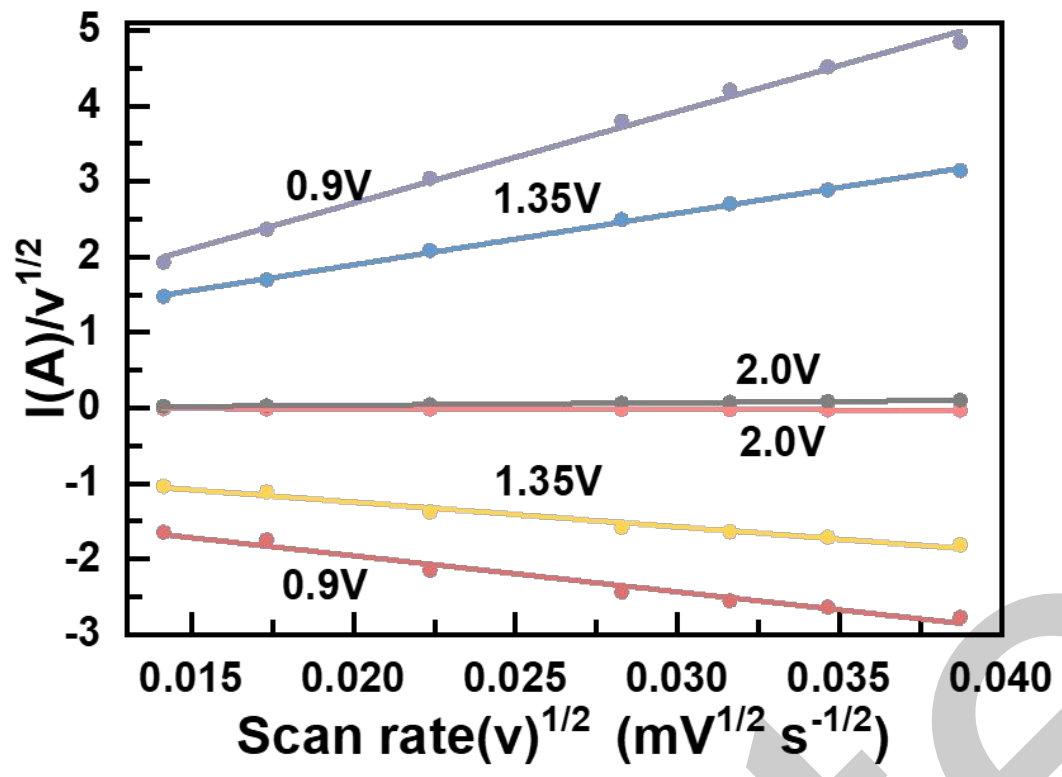

Figure S7 The plot of I(A) / $\mathrm{v}^{1 / 2}$ versus square root of scan rate $\mathrm{v}^{1 / 2}$ at different potentials with corresponding slopes values to estimate $k_{1}$ and $k_{2}$ constants for HGCN-1000.

(a)

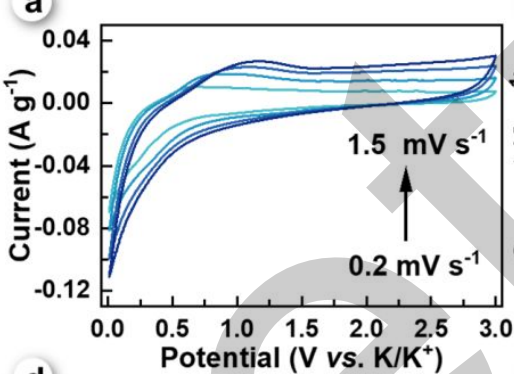

d)

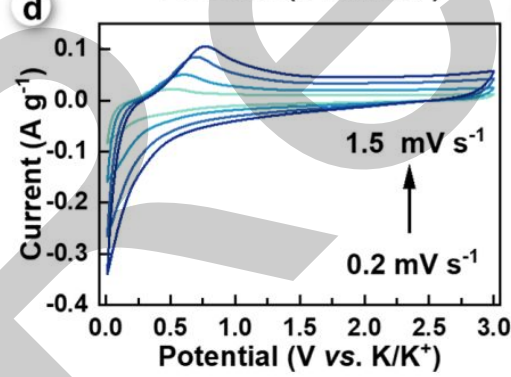

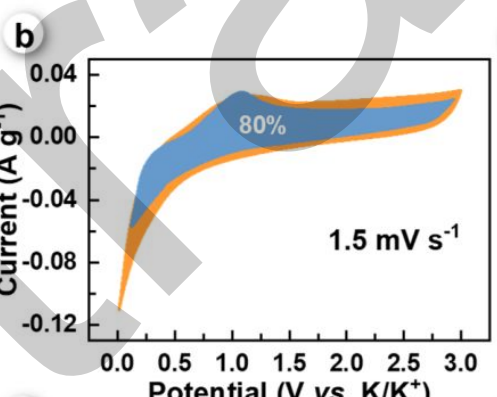

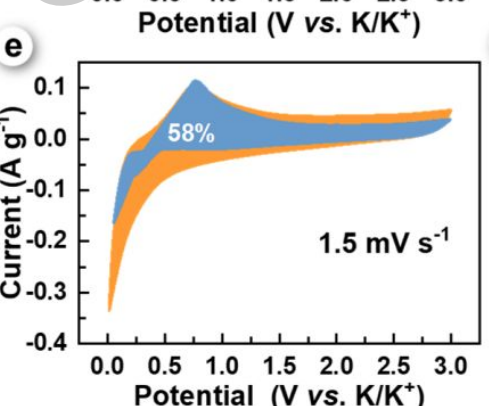

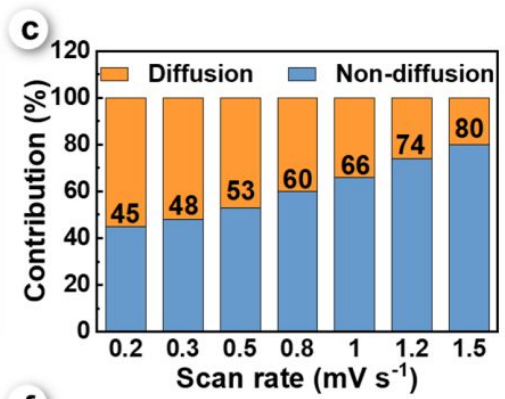

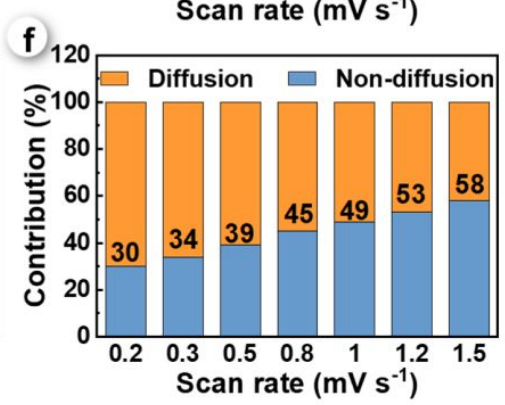

Figure S8 CV profiles measured at different scan rates from 0.2 to $1.5 \mathrm{mV} \mathrm{s}^{-1}$ and the corresponding capacitive contributions varying with scan rate for (a-c) HGCN-800 and (d-f) HGCN-1200. 
Table S1 Comparision of the electrochemical performance of HGCNs with competitive materials utilized as anodes for PIBs.

\begin{tabular}{|c|c|c|c|c|}
\hline Carbon anode & $\begin{array}{l}\text { Reversible } \\
\text { capacity }\end{array}$ & Cycle performance & Rate performance & \\
\hline HGCN-1000 & $\begin{array}{l}402.2 \mathrm{mAh}^{-1} \text { at } \\
30 \mathrm{~mA} \mathrm{~g}^{-1}\end{array}$ & $\begin{array}{l}309.1 \mathrm{mAh}^{-1} \text { after } 500 \\
\text { cycles at } 50 \mathrm{~mA} \mathrm{~g}^{-1} \\
160.5 \mathrm{mAh} \mathrm{g}^{-1} \text { after } \\
1000 \text { cycles at } 1 \mathrm{~A} \mathrm{~g}^{-1}\end{array}$ & $138.6 \mathrm{mAh} g$ & $\begin{array}{l}\text { This } \\
\text { work }\end{array}$ \\
\hline $\begin{array}{l}\text { Activated carbon } \\
\text { from graphite by } \\
\mathrm{KOH} \text { activation }\end{array}$ & $\begin{array}{l}260 \mathrm{mAh} \mathrm{g}^{-1} \text { at } 50 \\
\mathrm{~mA} \mathrm{~g}^{-1}\end{array}$ & $\begin{array}{l}100.3 \mathrm{mAh} \mathrm{g}^{-1} \text { after } 100 \\
\text { cycles } 200 \mathrm{~mA} \mathrm{~g}^{-1}\end{array}$ & & 1 \\
\hline Expanded graphite & $\begin{array}{l}263 \mathrm{mAh} \mathrm{g}^{-1} 10 \\
\mathrm{~mA} \mathrm{~g}^{-1}\end{array}$ & $\begin{array}{l}228 \mathrm{mAh} \mathrm{g}^{-1} \text { after } 200 \\
\text { cycles } 50 \mathrm{~mA} \mathrm{~g}^{-1}\end{array}$ & $\begin{array}{l}175 \mathrm{mAh} \mathrm{g}^{-1} \text { at } 200 \mathrm{~mA} \\
\mathrm{~g}^{-1}\end{array}$ & 2 \\
\hline $\begin{array}{l}\text { Polynanocrystalline } \\
\text { Graphite }\end{array}$ & $\begin{array}{l}224 \mathrm{mAh} \mathrm{g}^{-1} \text { at } 20 \\
\mathrm{~mA} \mathrm{~g}^{-1}\end{array}$ & $\begin{array}{l}112 \mathrm{mAh} \mathrm{g}^{-1} \text { after } 240 \\
\text { cycles at } 100 \mathrm{~mA} \mathrm{~g}^{-1}\end{array}$ & $13.6 \mathrm{mAh} \mathrm{g}^{-1}$ at $1 \mathrm{~A} \mathrm{~g}^{-1}$ & 3 \\
\hline $\begin{array}{l}\text { Graphitic carbon } \\
\text { nanocage }\end{array}$ & $\begin{array}{l}212 \mathrm{mAh} \mathrm{g}^{-1} \text { at } 0.2 \\
\mathrm{C}\end{array}$ & $\begin{array}{l}195 \mathrm{mAh} \mathrm{g}^{-1} \text { after } 100 \\
\text { cycles at } 0.2 \mathrm{C}\end{array}$ & $56 \mathrm{mAh} \mathrm{g}^{-1}$ at $3 \mathrm{C}$ & 4 \\
\hline $\begin{array}{l}\text { N-doped graphitic } \\
\text { nanocarbons }\end{array}$ & $\begin{array}{l}369 \mathrm{mAh} \mathrm{g}^{-1} \text { at } 50 \\
\mathrm{~mA} \mathrm{~g}^{-1}\end{array}$ & $\begin{array}{l}189 \mathrm{mAh} \mathrm{g}^{-1} \text { after } 200 \\
\text { cycles } 200 \mathrm{~mA} \mathrm{~g}^{-1}\end{array}$ & $152 \mathrm{mAh} \mathrm{g}^{-1}$ at $1 \mathrm{~A} \mathrm{~g}^{-1}$ & 5 \\
\hline $\begin{array}{ll}\text { Potato } & \text { derived } \\
\text { biomass } & \text { porous } \\
\text { carbon } & \end{array}$ & $\begin{array}{l}248 \mathrm{mAh} \mathrm{g}^{-1} \text { at } 100 \\
\mathrm{~mA} \mathrm{~g}^{-1}\end{array}$ & $\begin{array}{l}200 \mathrm{mAh} \mathrm{g}^{-1} \text { after } 400 \\
\text { cycles } 500 \mathrm{~mA} \mathrm{~g}^{-1}\end{array}$ & $150 \mathrm{mAh} \mathrm{g}^{-1}$ at $1 \mathrm{~A} \mathrm{~g}^{-1}$ & 6 \\
\hline $\begin{array}{l}\text { Bacterial-derived } \\
\text { hierarchical porous } \\
\text { carbon }\end{array}$ & $\begin{array}{l}230 \mathrm{mAh} \mathrm{g}^{-1} \text { at } 80 \\
\mathrm{~mA} \mathrm{~g}^{-1}\end{array}$ & $\begin{array}{l}158 \mathrm{mAh} \mathrm{g}^{-1} \text { after } 2000 \\
\text { cycles } 1 \mathrm{~A} \mathrm{~g}^{-1}\end{array}$ & $164 \mathrm{mAh} \mathrm{g}^{-1}$ at $1 \mathrm{~A} \mathrm{~g}^{-1}$ & 7 \\
\hline Mesoporous carbon & $\begin{array}{l}307.4 \mathrm{mAh} \mathrm{g}^{-1} \text { at } \\
50 \mathrm{~mA} \mathrm{~g}^{-1}\end{array}$ & $\begin{array}{l}146.5 \mathrm{mAh} \mathrm{g}^{-1} \text { after } \\
1000 \text { cycles at } 1 \mathrm{~A} \mathrm{~g}^{-1}\end{array}$ & ${ }_{1}^{144.2 \mathrm{mAh} \mathrm{g}^{-1} \text { at } 1 \mathrm{~A} \mathrm{~g}^{-}}$ & 8 \\
\hline $\begin{array}{l}\text { Porous carbon } \\
\text { nanofiber }\end{array}$ & $\begin{array}{l}272 \mathrm{mAh} \mathrm{g}^{-1} \text { at } 20 \\
\mathrm{~mA} \mathrm{~g}^{-1}\end{array}$ & $\begin{array}{l}270 \mathrm{mAh} \mathrm{g}^{-1} \text { after } 80 \\
\text { cycles at } 20 \mathrm{~mA} \mathrm{~g}^{-1}\end{array}$ & $140 \mathrm{mAh} \mathrm{g}^{-1}$ at $5 \mathrm{~A} \mathrm{~g}^{-1}$ & 9 \\
\hline Carbon spheres & $\begin{array}{l}314 \mathrm{mAh} \mathrm{g}^{-1} \text { at } 50 \\
\mathrm{~mA} \mathrm{~g}^{-1}\end{array}$ & $\begin{array}{l}218 \mathrm{mAh} \mathrm{g}^{-1} \text { after } 500 \\
\text { cycles at } 200 \mathrm{~mA} \mathrm{~g}^{-1}\end{array}$ & $121 \mathrm{mAh} \mathrm{g}^{-1}$ at $5 \mathrm{~A} \mathrm{~g}^{-1}$ & 10 \\
\hline $\begin{array}{l}\text { Skimmed cotton- } \\
\text { derived hard carbon }\end{array}$ & $\begin{array}{l}253 \mathrm{mAh} \mathrm{g}^{-1} \text { at } 40 \\
\mathrm{~mA} \mathrm{~g}^{-1}\end{array}$ & $\begin{array}{l}240 \mathrm{mAh} \mathrm{g}^{-1} \text { after } 150 \\
\text { cycles at } 200 \mathrm{~mA} \mathrm{~g}^{-1}\end{array}$ & $165 \mathrm{mAh} \mathrm{g}^{-1}$ at $4 \mathrm{~A} \mathrm{~g}^{-1}$ & 11 \\
\hline $\begin{array}{l}\text { Hard-soft composite } \\
\text { carbon }\end{array}$ & $260 \mathrm{mAh} \mathrm{g}^{-1}$ at $1 \mathrm{C}$ & $\begin{array}{l}200 \mathrm{mAh} \mathrm{g}^{-1} \text { after } 200 \\
\text { cycles at } 1 \mathrm{C}\end{array}$ & $190 \mathrm{mAh} \mathrm{g}^{-1}$ at of $2 \mathrm{C}$ & 12 \\
\hline
\end{tabular}




\begin{tabular}{|c|c|c|c|c|}
\hline $\begin{array}{ll}\text { Hollow } & \text { carbon } \\
\text { architecture } & \end{array}$ & $\begin{array}{l}340 \mathrm{mAh} \mathrm{g}^{-1} \text { at } \\
0.1 \mathrm{C}\end{array}$ & $\begin{array}{l}250 \mathrm{mAh} \mathrm{g}^{-1} \text { after } 150 \\
\text { cycles at } 0.5 \mathrm{C}\end{array}$ & & 13 \\
\hline $\begin{array}{l}N \text {-doped } \\
\text { hierarchically porous } \\
\text { carbon }\end{array}$ & $\begin{array}{l}349.4 \mathrm{mAh} \mathrm{g}^{-1} \text { at } \\
50 \mathrm{~mA} \mathrm{~g}^{-1}\end{array}$ & $\begin{array}{l}296.8 \mathrm{mAh} \mathrm{g}^{-1} \text { after } 100 \\
\text { cycles at } 50 \mathrm{~mA} \mathrm{~g}^{-1}\end{array}$ & $\begin{array}{l}193.1 \mathrm{mAh} \mathrm{g}^{-1} \text { at } 500 \\
\mathrm{~mA} \mathrm{~g}^{-1}\end{array}$ & 14 \\
\hline $\begin{array}{l}\text { N/O dual-doped hard } \\
\text { carbon }\end{array}$ & $\begin{array}{l}365 \mathrm{mAh} \mathrm{g}^{-1} \text { at } 25 \\
\mathrm{~mA} \mathrm{~g}^{-1}\end{array}$ & $\begin{array}{l}230.6 \mathrm{mAh} \mathrm{g}^{-1} \text { after } 100 \\
\text { cycles at } 50 \mathrm{~mA} \mathrm{~g}^{-1}\end{array}$ & $118 \mathrm{mAh} \mathrm{g}^{-1}$ at $3 \mathrm{~A} \mathrm{~g} \mathrm{~g}^{-1}$ & 15 \\
\hline $\begin{array}{l}\text { S/O co-doped porous } \\
\text { hard carbon } \\
\text { microspheres }\end{array}$ & $\begin{array}{l}221.3 \mathrm{mAh} \mathrm{g}^{-1} \text { at } \\
50 \mathrm{~mA} \mathrm{~g}^{-1}\end{array}$ & $\begin{array}{l}226 \mathrm{mAh} \mathrm{g}^{-1} \text { after } 100 \\
\text { cycles at } 50 \mathrm{~mA} \mathrm{~g}^{-1}\end{array}$ & $158 \mathrm{mAh}$ & 16 \\
\hline $\begin{array}{l}\text { High pyridine } N- \\
\text { doped porous carbon }\end{array}$ & $\begin{array}{l}587.6 \mathrm{mAh} \mathrm{g}^{-1} \text { at } \\
50 \mathrm{~mA} \mathrm{~g}^{-1}\end{array}$ & $\begin{array}{l}231.6 \mathrm{mAh} \mathrm{g}^{-1} \text { after } \\
2000 \text { cycles at } 50 \mathrm{~mA} \mathrm{~g} \\
1\end{array}$ & & 17 \\
\hline $\begin{array}{l}N \text {-doped porous } \\
\text { carbon monolith }\end{array}$ & $\begin{array}{l}487 \mathrm{mAh} \mathrm{g}^{-1} \text { at } 20 \\
\mathrm{~mA} \mathrm{~g}^{-1}\end{array}$ & $\begin{array}{l}351 \mathrm{mAh} \mathrm{g}^{-1} \text { after } 60 \\
\text { cycles at } 20 \mathrm{~mA} \mathrm{~g}^{-1}\end{array}$ & $199 \mathrm{mAh} \mathrm{g}^{-1}$ at $2 \mathrm{~A} \mathrm{~g}^{-1}$ & 18 \\
\hline $\begin{array}{l}\text { Chitin-derived } \\
\text { nitrogen-doped } \\
\text { carbon nanofibers }\end{array}$ & $\begin{array}{l}240 \mathrm{mAh} \mathrm{g}^{-1} \text { at } 0.2 \\
\mathrm{C}\end{array}$ & $\begin{array}{l}215.2 \mathrm{mAh} \mathrm{g}^{-1} \text { after } 100 \\
\text { cycles at } 0.2 \mathrm{C}\end{array}$ & $84.5 \mathrm{mAh} \mathrm{g}^{-1}$ at $5 \mathrm{C}$ & 19 \\
\hline $\begin{array}{l}\mathrm{N} / \mathrm{S} \text { co-doped carbon } \\
\text { microboxes }\end{array}$ & $\begin{array}{l}452.3 \mathrm{mAh} \mathrm{g}^{-1} \text { at } \\
50 \mathrm{~mA} \mathrm{~g}^{-1}\end{array}$ & $\begin{array}{l}180 \mathrm{mAh} \mathrm{g}^{-1} \text { after } 1000 \\
\text { cycles at } 500 \mathrm{~mA} \mathrm{~g}^{-1}\end{array}$ & ${ }_{1}^{151.6 \mathrm{mAh} \mathrm{g}^{-1} \text { at } 1 \mathrm{~A} \mathrm{~g}^{-}}$ & 20 \\
\hline $\begin{array}{l}\text { N/O-rich carbon } \\
\text { nanofiber }\end{array}$ & $200 \mathrm{mAh} \mathrm{g}^{-1}$ at $1 \mathrm{C}$ & $\begin{array}{l}170 \mathrm{mAh} \mathrm{g}^{-1} \text { after } 1900 \\
\text { cycles at } 1 \mathrm{C}\end{array}$ & $110 \mathrm{mAh} \mathrm{g}^{-1}$ at $10 \mathrm{C}$ & 21 \\
\hline $\begin{array}{l}\text { Phosphorus and } \\
\text { oxygen dual-doped } \\
\text { graphene }\end{array}$ & $566 \mathrm{mAh}$ & $\begin{array}{l}160 \mathrm{mAh} \mathrm{g}^{-1} \text { after } 600 \\
\text { cycles at } 2 \mathrm{~A} \mathrm{~g}^{-1}\end{array}$ & $165 \mathrm{mAh} \mathrm{g}^{-1}$ at $2 \mathrm{~A} \mathrm{~g}^{-1}$ & 22 \\
\hline $\begin{array}{l}\text { Nitrogen-doped } \\
\text { bamboo-like carbon } \\
\text { nanotubes }\end{array}$ & $\begin{array}{l}380.3 \mathrm{mAh} \mathrm{g}^{-1} \text { at } \\
50 \mathrm{~mA} \mathrm{~g}^{-1}\end{array}$ & $\begin{array}{l}204 \mathrm{mAh} \mathrm{g}^{-1} \text { after } 1000 \\
\text { cycles at } 50 \mathrm{~mA} \mathrm{~g}^{-1}\end{array}$ & $186 \mathrm{mAh} \mathrm{g}^{-1}$ at $1 \mathrm{~A} \mathrm{~g}^{-1}$ & 23 \\
\hline $\begin{array}{l}\text { Nitrogen-doped } \\
\text { carbon nanotubes }\end{array}$ & $\begin{array}{l}292.7 \mathrm{mAh} \mathrm{g}^{-1} \text { at } \\
50 \mathrm{~mA} \mathrm{~g}^{-1}\end{array}$ & $\begin{array}{l}254.7 \mathrm{mAh} \mathrm{g}^{-1} \text { after } 300 \\
\text { cycles at } 200 \mathrm{~mA} \mathrm{~g}^{-1}\end{array}$ & $102 \mathrm{mAh} \mathrm{g}^{-1}$ at $2 \mathrm{~A} \mathrm{~g}^{-1}$ & 24 \\
\hline $\begin{array}{l}\text { Nitrogen doped } \\
\text { carbon nanofiber }\end{array}$ & $\begin{array}{l}368 \mathrm{mAh} \mathrm{g}^{-1} \text { at } 25 \\
\mathrm{~mA} \mathrm{~g}^{-1}\end{array}$ & $\begin{array}{l}248 \mathrm{mAh} \mathrm{g} \mathrm{g}^{-1} \text { after } 100 \\
\text { cycles at } 25 \mathrm{~mA} \mathrm{~g}^{-1}\end{array}$ & $101 \mathrm{mAh} \mathrm{g}^{-1}$ at $20 \mathrm{~A} \mathrm{~g}^{-1}$ & 25 \\
\hline
\end{tabular}




\section{References}

(1) Tai, Z.; Zhang, Q.; Liu, Y.; Liu, H.; Dou, S. Activated Carbon from the Graphite with Increased Rate Capability for the Potassium Ion Battery. Carbon 2017, 123, 54-61.

(2) An, Y.; Fei, H.; Zeng, G.; Ci, L.; Xi, B.; Xiong, S.; Feng, J. Commercial Expanded Graphite as a Low-Cost, Long-Cycling Life Anode for Potassium-Ion Batteries with Conventional Carbonate Electrolyte. Int. J. Hydrogen Energ. 2018, 378, 66-72.

(3) Xing, Z.; Qi, Y.; Jian, Z.; Ji, X. Polynanocrystalline Graphite: A New Carbon Anode with Superior Cycling Performance for K-Ion Batteries. ACS Appl. Mater. Interfaces 2017, 9, 43434351.

(4) Cao, B.; Zhang, Q.; Liu, H.; Xu, B.; Zhang, S.; Zhou, T.; Mao, J.; Pang, W. K.; Guo, Z.; Li, A.; Zhou, J.; Chen, X.; Song, H. Graphitic Carbon Nanocage as a Stable and High Power Anode for Potassium-Ion Batteries. Adv. Energy Mater. 2018, 8. 1801149.

(5) Zhang, W.; Ming, J.; Zhao, W.; Dong, X.; Hedhili, M. N.; Costa, P. M. F. J.; Alshareef, H.

N. Graphitic Nanocarbon with Engineered Defects for High-Performance Potassium-Ion Battery Anodes. Adv. Funct. Mater. 2019, 29, 1903641.

(6) Cao, W.; Zhang, E.; Wang, J.; Liu, Z.; Ge, J.; Yu, X.; Yang, H.; Lu, B. Potato Derived Biomass Porous Carbon as Anode for Potassium Ion Batteries. Electrochim. Acta 2019, 293, 364-370.

(7) Li, H.; Cheng, Z.; Zhang, Q.; Natan, A.; Yang, Y.; Cao, D.; Zhu, H. Bacterial-Derived, Compressible, and Hierarchical Porous Carbon for High-Performance Potassium-Ion Batteries. Nano Lett. 2018, 18, 7407-7413.

(8) Wang, W.; Zhou, J.; Wang, Z. Zhao, L.; Li, P.; Yang, Y.; Yang, C.; Huang, H.; Guo, S. Short-Range Order in Mesoporous Carbon Boosts Potassium-Ion Battery Performance. Adv. Energy Mater. 2018, 8, 1701648.

(9) Zhao, X.; Xiong, P.; Meng, J.; Liang, Y.; Wang, J.; Xu, Y. High Rate and Long Cycle Life Porous Carbon Nanofiber Paper Anodes for Potassium-Ion Batteries. J. Mater. Chem. A 2017, $5,19237-19244$.

(10) Zhang, H.; He, H.; Luan, J.; Huang, X.; Tang, Y.; Wang, H. Adjusting the Yolk-Shell Structure of Carbon Spheres to Boost the Capacitive $\mathrm{K}^{+}$Storage Ability. J. Mater. Chem. A 2018, 6, 23318-23325

(11) He, X.; Liao, J.; Tang, Z.; Xiao, L.; Ding, X.; Hu, Q.; Wen, Z.; Chen, C. Highly Disordered Hard Carbon Derived from Skimmed Cotton as a High-Performance Anode Material for Potassium-Ion Batteries. J. Power Sources 2018, 396, 533-541.

(12) Jian, Z.; Hwang, S.; Li, Z.; Hernandez, A. S.; Wang, X.; Xing, Z.; Su, D.; Ji, X. Hard-Soft 
Composite Carbon as a Long-Cycling and High-Rate Anode for Potassium-Ion Batteries. Adv. Funct. Mater. 2017, 27, 1700324.

(13) Bin, D. S.; Lin, X. J.; Sun, Y. G.; Xu, Y. S.; Zhang, K.; Cao, A. M.; Wan, L. J. Engineering Hollow Carbon Architecture for High-Performance K-Ion Battery Anode. J. Am. Chem. Soc. 2018, 140, 7127-7134.

(14) Qi, X.; Huang, K.; Wu, X.; Zhao, W.; Wang, H.; Zhuang, Q.; Ju, Z. Novel Fabrication of $\mathrm{N}$-Doped Hierarchically Porous Carbon with Exceptional Potassium Storage Properties. Carbon 2018, 131, 79-85.

(15) Yang, J.; Ju, Z.; Jiang, Y.; Xing, Z.; Xi, B.; Feng, J.; Xiong, S. Enhanced Capacity and Rate Capability of Nitrogen/Oxygen Dual-Doped Hard Carbon in Capacitive Potassium-Ion Storage. Adv. Mater. 2018, 30, 1700104.

(16) Chen, M.; Wang, W.; Liang, X.; Gong, S.; Liu, J.; Wang, Q.; Guo, S.; Yang, H. Sulfur/Oxygen Codoped Porous Hard Carbon Microspheres for High-Performance PotassiumIon Batteries. Adv. Energy Mater. 2018, 8, 1800171.

(17) Li, Y.; Yang, C.; Zheng, F.; Ou, X.; Pan, Q.; Liu, Y.; Wang, G. High Pyridine N-Doped Porous Carbon Derived from Metal-Organic Frameworks for Boosting Potassium-Ion Storage. J. Mater. Chem. A 2018, 6, 17959-17966.

(18) Xie, Y.; Chen, Y.; Liu, L.; Tao, P.; Fan, M.; Xu, N.; Shen, X.; Yan, C. Ultra-High Pyridinic $N$-Doped Porous Carbon Monolith Enabling High-Capacity K-Ion Battery Anodes for Both Half-Cell and Full-Cell Applications. Adv. Mater. 2017, 29, 1702268.

(19) Hao, R.; Lan, H.; Kuang, C.; Wang, H.; Guo, L. Superior Potassium Storage in ChitinDerived Natural Nitrogen-Doped Carbon Nanofibers. Carbon 2018, 128, 224-230.

(20) Li, Y.; Zhong, W.; Yang, C.; Zheng, F.; Pan, Q.; Liu, Y.; Wang, G.; Xiong, X.; Liu, M. N/S Codoped Carbon Microboxes with Expanded Interlayer Distance toward Excellent Potassium Storage. Chem. Eng. J. 2019, 358, 1147-1154.

(21) Adams, R. A.; Syu, J. M.; Zhao, Y.; Lo, C. T.; Varma, A.; Pol, V. G. Binder-Free N-and O-Rich Carbon Nanofiber Anodes for Long Cycle Life K-Ion Batteries. ACS Appl. Mater. Interfaces 2017, 9, 17872-17881.

(22) Ma, G.; Huang, K.; Ma, J.-S.; Ju, Z.; Xing, Z.; Zhuang, Q. C. Phosphorus and Oxygen Dual-Doped Graphene as Superior Anode Material for Room-Temperature Potassium-Ion Batteries. J. Mater. Chem. A 2017, 5, 7854-7861.

(23) Liu, Y.; Yang, C.; Pan, Q.; Li, Y.; Wang, G.; Ou, X.; Zheng, F.; Xiong, X.; Liu, M.; Zhang, Q. Nitrogen-Doped Bamboo-Like Carbon Nanotubes as Anode Material for High Performance Potassium Ion Batteries. J. Mater. Chem. A 2018, 6, 15162-15169. 
<smiles>C1#C[C@@H](C2C#C2)C1</smiles> 